\title{
REVIEW
}

\section{Adipose tissue in obesity and obstructive sleep apnoea}

\author{
M.R. Bonsignore*,\#, W.T. McNicholas`, J.M. Montserrat ${ }^{+}$and J. Eckel ${ }^{\S}$
}

ABSTRACT: A European Respiratory Society research seminar on "Metabolic alterations in obstructive sleep apnoea (OSA)" was jointly organised in October 2009 together with two EU COST actions (Cardiovascular risk in the obstructive sleep apnoea syndrome, action B26, and Adipose tissue and the metabolic syndrome, action BM0602) in order to discuss the interactions between obesity and OSA.

Such interactions can be particularly significant in the pathogenesis of metabolic abnormalities and in increased cardiovascular risk in OSA patients. However, studying the respective role of OSA and obesity is difficult in patients, making it necessary to refer to animal models or in vitro systems. Since most OSA patients are obese, their management requires a multidisciplinary approach.

This review summarises some aspects of the pathophysiology and treatment of obesity, and the possible effects of sleep loss on metabolism. OSA-associated metabolic dysfunction (insulin resistance, liver dysfunction and atherogenic dyslipidaemia) is discussed from the perspective of both obesity and OSA in adults and children.

Finally, the effects of treatment for obesity or OSA, or both, on cardio-metabolic variables are summarised. Further interdisciplinary research is needed in order to develop new comprehensive treatment approaches aimed at reducing sleep disordered breathing, obesity and cardiovascular risk.

KEYWORDS: Adipocyte, dyslipidaemia, hypoxia, liver dysfunction, obesity

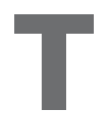
he worldwide obesity epidemic has fostered investigation on adipose tissue, in order to prevent obesity-linked morbidity and develop effective treatment. Obesity is a risk factor for diabetes and cardiovascular events [1, 2] and increases mortality, especially in middleaged adults [3]. Obesity rates are also increasing in children $[4,5]$. Since obese children tend to become obese adults [6], the cardio-metabolic disease associated with obesity could begin in childhood [7].

Adipose tissue is a central player in metabolic regulation through the production and release of multiple adipokines [8]. Moreover, adipocytes and inflammatory cells, such as macrophages, show a high degree of interaction in obesity $[9,10]$. The resulting picture is complex and, at present, incomplete. Recent research has explored new directions, such as the pathophysiology of different fat depots in the body [11], the role of hypoxia [12], and the interactions between adipose tissue and the central nervous system in response to nutrient excess [13]. Obesity has also been related to chronic sleep loss, typical of the current lifestyle in both adults and children [14, 15].

Obesity is a common finding and a major pathogenetic factor in obstructive sleep apnoea (OSA) in adults $[16,17]$ and children [18-20]. OSA is characterised by recurring episodes of upper airway obstruction during sleep [21], intermittent hypoxia [22], sleep fragmentation [23], excessive daytime sleepiness [21] and increased cardiovascular risk [24]. Upper airway collapse during sleep can be prevented by the application of nasal continuous positive airway pressure (CPAP), which is the treatment of choice for moderateto-severe OSA in adults. In children, OSA is traditionally considered as a "local" disease due to high prevalence of adenotonsillar hypertrophy, and adenotosillectomy is usually performed; however, partial resolution of OSA is often observed, which probably reflects the additional impact of obesity [25, 26].

Changes in body weight are known to affect OSA severity [27-29]. Most adult patients with OSA

\section{AFFILIATIONS}

*Biomedical Dept of Internal and Specialistic Medicine (DIBIMIS), Section of Pneumology, University of Palermo,

\# Institute of Biomedicine and Molecular Immunology (IBIM), National Research Council (CNR), Palermo, Italy.

-Pulmonary and Sleep Disorders Unit, St. Vincent's University Hospital, Dublin, Ireland. +Sleep Laboratory, Hospital Clinic-IDIBAPS CIBERES, Barcelona, Spain.

${ }^{\S}$ German Diabetes Center,

Dusseldorf, Germany.

CORRESPONDENCE

M.R. Bonsignore

Biomedical Dept of Internal and Specialistic Medicine (DIBIMIS)

University of Palermo

c/o V Cervello Hospital

Via Trabucco 180

90146 Palermo

Italy

E-mail: marisa@ibim.cnr.it

Received:

March 242010

Accepted after revision:

July 302011

First published online:

Sept 152011 
have central obesity and increased visceral fat [30], the latter being associated with neck adiposity, increased upper airway fat [31] and metabolic abnormalities [32], even in normal weight subjects. Sex-related differences in the amount of visceral fat could contribute to the higher prevalence of OSA in males [33]. In children, besides the classic OSA phenotype associated with adenotonsillar hypertrophy [34] and growth failure [35], it is possible to identify an obese OSA phenotype, similar to adult OSA [34].

It is conceivable that OSA and obesity may interact and potentiate their detrimental consequences. OSA-associated metabolic abnormalities have been reproduced in animal models exposed to a pattern of intermittent hypoxia similar to that found in humans with sleep disordered breathing [36, 37]. However, hypoxia of adipocytes could play an important role in the metabolic disturbances associated with obesity [8, 38]. In addition, OSA and obesity share common mechanisms such as inflammatory activation [39], oxidative stress [39] and increased sympathetic activity [40].

In order to discuss the complex relationship between OSA and obesity, a second research seminar on the "Metabolic effects of OSA" was organised in October 2009 by the European Respiratory Society and two EU-funded actions of the COST programme (Cooperation in Scientific and Technological Research), namely COST actions B26 (Cardiovascular risk in the obstructive sleep apnoea syndrome) and BM0602 (Adipose tissue and the metabolic syndrome). The first research seminar took place in 2007, and its focus was primarily on the pathogenesis of insulin resistance (IR) in OSA [36].

The purpose of this review is to provide an overview on the pathophysiology of obesity, including an essential description of the main aspects of adipose tissue biology, the pathogenesis and the implications of IR in tissues such as skeletal muscle and liver, the possible role of sleep loss in obesity, and current treatment for obesity. With this background, the role played by OSA in the pathogenesis of metabolic abnormalities in adults and children will be briefly reviewed, together with the effects of OSA treatment. As for genetic interactions between OSA and obesity, which were also discussed during the seminar, the interested reader is referred to several recently published reviews [41-43].

\section{ADIPOSE TISSUE PATHOPHYSIOLOGY, IR AND METABOLIC SYNDROME}

The aim of this section is to discuss some features of obesity that are important in the context of OSA, namely the types and distribution of adipose tissue in obesity, and the mechanisms of adipocyte dysfunction.

\section{Types and distribution of adipose tissue in obesity}

Adipose tissue exerts important endocrine functions involving multiple crosstalk with other organs and tissues [44]. Adipocytes produce hormones, cytokines and many other proteins and peptides, collectively called "adipokines", leading to fine tuning of fuel utilisation, energy homeostasis and cardiovascular function [8, 45-47]. In addition, pre-adipocytes, lymphocytes, macrophages and endothelial cells contribute to the secretory output of adipose tissue and play a key role for the endocrine activity of the different fat depots.
Obesity is characterised by the expansion of white adipose tissue, as a result of increased size (hypertrophy), and, additionally, by an increased number of adipocytes (hyperplasia) [48]. The number and size of adipocytes vary according to localisation of fat [48], diet [49], genetic factors [50], sympathetic innervation [51] and sex [52]. Visceral adiposity is generally associated with hypertrophy of adipocytes [53]. A modest amount of brown adipose tissue (BAT) is also present in humans, its main function being heat production rather than energy storage. The peculiar anatomical and functional characteristics of BAT have been recently summarised [54-56].

The localisation of excess white adipose tissue in the body carries relevant metabolic consequences. Increased visceral fat mass is associated with more severe health effects compared to peripheral obesity, which is characterised by predominant accumulation of subcutaneous fat [57]. The expansion of visceral fat increases the risk of developing IR, type-II diabetes, atherosclerosis, OSA, steatohepatitis, and cardio- and cerebrovascular disease $[3,58,59]$. Many clinical and biochemical factors associated with increased cardiovascular risk (i.e. dyslipidaemia, arterial hypertension, hyperglycaemia, hyperuricaemia and microalbuminuria) are often present in visceral (or central) obesity. The term "adiposopathy" has been proposed to indicate the strong link between visceral fat and obesity-associated metabolic abnormalities [60].

Recent data highlight the role of fat localisation in modulating adipocyte function. Besides the classic distinction between visceral and subcutaneous fat, the latter can be subdivided into superficial and deep, with the deep fraction sharing many features with visceral fat [61]. Ectopic fat depots can be found in the epicardial, periadvential and perirenal regions, and in the pancreas, skeletal muscle and bone marrow [47]. The physiology of adipose tissue in these localisations, and the cellular source of adipokines and inflammatory mediators, are incompletely understood but could contribute to the pathogenesis of obesity-associated abnormalities [47]. Specifically, epicardial fat is a true visceral fat depot, and a tight association of epicardial fat mass with risk of cardiovascular disease has been recently reported [62].

Clinically, increased abdominal circumference is the best marker of visceral obesity and predicts overall mortality [3]. To improve the clinical recognition of central obesity, the metabolic syndrome (MetS) has been defined as the association of some risk factors (i.e. increased waist circumference, high blood pressure and dyslipidaemia) [59]. The widely used National Health and Nutrition Examination Survey/Adult Treatment Panel III definition is based on simple criteria [63], but its clinical or epidemiological usefulness is not entirely clear [64].

Identification of specific metabolic phenotypes may help to focus on high-risk patients. For example, $\sim 20 \%$ of the obese population are metabolically healthy (MHO) [65]. The MHO phenotype is associated with early onset of obesity, predominance of subcutaneous over visceral fat, and a more favourable cardiovascular profile compared to patients with central obesity [66]. Adipose tissue in the gluteofemoral region may play an important protective role against metabolic abnormalities and the associated cardiovascular risk, by acting as a metabolic sink for excess fat storage $[67,68]$. The $\mathrm{MHO}$ phenotype might be more common in obese pre-menopausal females, who appear relatively protected from cardio-metabolic risk [33] but show 
increased mortality associated with the MetS in the postmenopausal period [69]. Conversely, normal-weight metabolically obese subjects show an apparently lean phenotype, but their amount of visceral fat is larger than normal and associated with $\operatorname{IR}[32,65]$. There are some uncertainties about definitions [70], and longitudinal studies on cardio-metabolic risk in obesity subtypes are still lacking.

The functional attitudes of visceral and subcutaneous adipocytes are programmed quite early during development and differentiation [71]. Adipocyte precursors are multi-potent cells that reside in each fat depot and possess depot-specific genetic, biochemical and metabolic features [72]. Metabolic activity is higher in visceral than in subcutaneous fat [11], and adipocytes located in the abdominal region display distinct features compared to adipocytes from other depots [73, 74] in both normal-weight and obese subjects. Visceral adipose tissue from non-obese humans responded faster and more intensely than subcutaneous adipose tissue to glucose or insulin exposure in vitro, with larger release of adiponectin, tumour necrosis factor (TNF)- $\alpha$ and leptin [11]. Visceral adipocytes from obese subjects released larger amounts of inflammatory cytokines, such as interleukin (IL)-1 $\beta$, IL-6 and IL-8, and adipokines such as leptin, compared to visceral adipocytes from lean subjects [75]. Increased visceral fat and inflammation of adipose tissue were recently found in morbidly obese insulin-resistant subjects compared to weight-matched insulin-sensitive subjects, while the amount of subcutaneous fat was similar in the two groups [53]. Thus, a specific dysfunction of visceral adipocytes is considered as the pathophysiological basis for the negative consequences of abdominal obesity.

A thorough discussion of adipokines is beyond the scope of this paper, but can be found in several recent articles [8, 45-47, 76]. Leptin and adiponectin will be briefly discussed since they exert complex and unique actions, and have been studied in patients with OSA. For both adipokines, higher circulating levels are found in females than in males [76], indicating that sex-related fat distribution may affect their expression and release [67].

Leptin is a polypeptide hormone produced by adipocytes in proportion to their triglyceride content, and is a major player in appetite regulation in the hypothalamus. Subcutaneous fat is the main site of production of leptin, and leptin release from samples of subcutaneous fat cultured in vitro correlates with the circulating leptin levels found in vivo in the same individuals [76]. Human obesity is usually associated with high plasma leptin and attenuated leptin signalling (leptin resistance) [77], while defects in the leptin or leptin receptor genes are rare in clinical practice but have been fundamental to the understanding of the physiology of leptin in animal models [78]. Leptin might be involved in the pathogenesis of hypoventilation disorders [79] and its transcription is activated by exposure to continuous severe hypoxia in vitro [80]. In recent years, the role of leptin in immune function and inflammation has been increasingly studied [81], and some data indicate that leptin could contribute to the pathogenesis of atherosclerotic lesions by promoting inflammation [82]. All these data make leptin an interesting adipokine in the context of sleep disordered breathing.

Adiponectin exerts an insulin-sensitising action, and its levels are decreased in obesity [83-85]. Adiponectin has anti-atherogenic and anti-inflammatory properties, and its circulating levels are lower than normal in patients with type-II diabetes, MetS, hypertension and coronary artery disease [84]. Adiponectin is produced almost exclusively by mature adipocytes, and its expression is higher in subcutaneous than in visceral fat [86]. Importantly, adiponectin is found in the circulation in different oligomeric forms and it is now accepted that the so-called highmolecular-weight form is of key importance for the biological effects of this hormone [87]. Inflammatory mediators, such as TNF- $\alpha$ [88], and both continuous [89] and intermittent [90] hypoxia were found to inhibit adiponectin production in vitro. Adiponectin levels increase after weight loss or treatment with several drugs, such as fibrates, angiotensin-converting enzyme inhibitors, angiotensin II type I receptor blockers, thiazolidinediones, statin and some calcium channel blockers [91]. The protective role of adiponectin and its modulation by hypoxia suggest that it may be a useful marker of metabolic dysfunction in obesity and OSA.

\section{Mechanisms of adipose tissue dysfunction in obesity Inflammation}

The recognition of inflammation as a major player in adipocyte dysfunction has been an important advance in obesity research. Inflammation was first reported to contribute to the pathogenesis of IR in 1993, when TNF- $\alpha$ expression was demonstrated in adipose tissue of obese rodents and insulin sensitivity was restored after treatment with anti-TNF- $\alpha$ antibodies [92]. There is a long list of inflammatory mediators involved in obesity and IR [93], and obesity is considered as a state of chronic, low-grade inflammation [9]. As obesity develops, adipose tissue becomes infiltrated with macrophages [94]. Adipocyte-macrophage interactions contribute to the development of IR, but other immune cells, such as mast cells or lymphocytes, probably play a role [10, 95].

The adipocyte can secrete inflammatory cytokines and attract monocytes by producing monocyte chemoattractant protein (MCP)-1 [94]. In vitro, adipocytes and macrophages show considerable similarities in their gene expression and functional aspects [10]. Both hypoxia [96] and decreased adiponectin [97] may play a role in macrophage activation in obesity. In obese animals, macrophages are found in close relationship with dead adipocytes (crown-like structures) [98], suggesting that their recruitment is linked to phagocytosis of cellular debris. In addition, a shift from an anti- to a pro-inflammatory phenotype in adipose tissue macrophages has been demonstrated in both murine [99] and human [100] obesity. In obese subjects, adipose tissue macrophages show increased expression of TNF- $\alpha$ and inducible nitric oxide synthase, according to the classic proinflammatory activation pattern (M1). Conversely, in lean subjects, adipose tissue macrophages predominantly show the alternative pattern of activation (M2) characterised by overexpression, among other molecules, of the anti-inflammatory cytokine IL-10 [99].

Although inflammation contributes to the development of IR and MetS $[9,93]$, the sequence of events leading to the inflammatory response in the adipose tissue is incompletely defined. An increased adipocyte size may be an important signal, through dysregulation of insulin signalling at the level of insulin receptor substrates (IRS). Phosphorylation of IRS-1, an early event in insulin signalling [101], is decreased in large adipocytes [102]. Adipocyte size in visceral fat correlated with IR in severely obese 
patients, and a smaller adipocyte size was found in $\mathrm{MHO}$ patients compared to patients with the classic visceral obesity phenotype [103]. Adipocyte size also correlated with proliferation of adipose tissue-derived progenitor cells [104].

Activation of the nuclear factor- $\mathrm{B}$ pathway further interferes with IRS-1 phosphorylation [10]. Nutrient excess causes endoplasmic reticulum (ER) stress, characterised by a complex disturbance in protein synthesis, in the adipocyte [105]. The pathways of inflammation and ER stress appear to intersect at some crucial points, involving the protein kinases JNK1 and IKK $\beta$ [95]. Finally, mitochondrial dysfunction was also demonstrated in adipocytes exposed to hyperglycaemia [106]. Therefore, inflammation impacts on several cellular pathways, deeply disturbing adipocyte function.

\section{Hypoxia}

Expansion of adipose tissue causes oxygen deprivation in large adipocytes as their distance from the vasculature increases [12, 107]. In vitro exposure of human and murine adipocytes to prolonged hypoxia decreased phosphorylation of IRS-1 and IRS-2 and caused IR [108, 109]. Hypoxia in adipose tissue has been documented in obese humans [110-112] and mice [113, 114]. In adipocytes in culture, continuous hypoxia stimulated the expression and secretion of several inflammation-related adipokines, including IL-6, leptin, angiopoietin-like protein-4 and vascular endothelial growth factor [113-115]. Continuous hypoxia inhibited the production of adiponectin [89], while intermittent hypoxia (12 cycles per h for $6 \mathrm{~h}$ per day) was recently found to inhibit adiponectin secretion while upregulating its expression in adipocytes [90].

Many effects of hypoxia are mediated by the hypoxia-inducible factor (HIF)-1, a transcription factor resulting from the dimerisation of an $\alpha$-subunit, which is continuously degraded in the cytoplasm under normoxic conditions, and a $\beta$-subunit constitutively expressed by the cell [116]. When the oxygen level decreases, degradation of HIF- $1 \alpha$ is inhibited and its cytoplasmic level increases, making dimerisation of HIF, its translocation to the nucleus and the subsequent activation of transcription of several hypoxia-responsive genes all possible [116].

Exposure to continuous hypoxia causes multiple adjustments in cell metabolism, including a switch to anaerobic glycolysis. In adipocytes, continuous hypoxia increased the expression and protein level of the glucose transporter GLUT-1 [117], glucose uptake and release of lactate [118, 119], but decreased the expression of the insulin-dependent glucose transporter GLUT-4 [119]. Among the genes upregulated by hypoxia, expression of metallothionein-3 increased 600 -fold, suggesting a role possibly linked to its antioxidant properties [120]. Thus, in vitro data indicate that HIF-1 $\alpha$ activation may directly cause IR in adipocytes [108]. However, a recent study in mice with defective expression of HIF- $1 \alpha$ in adipose tissue found that these animals became more obese and insulin resistant when exposed to a highfat diet compared to wild-type mice [121]. Decreased energy expenditure associated with dysfunction of BAT appeared more important than IR in this in vivo model [121]. Therefore, further studies are needed to assess the role of hypoxia on brown and white adipose tissue in animal models and humans.

Recent measurements of tissue partial pressure of oxygen $\left(\mathrm{PO}_{2}\right)$ in lean rats during intermittent hypoxia or obstructive apnoea cycles of comparable duration, showed that tissue $\mathrm{PO}_{2}$ oscillations were blunted in visceral adipose tissue [122], suggesting the possibility that changes in blood flow to adipose tissue might also occur in this model. More data are needed to better understand the effects of intermittent hypoxia on adipose tissue in order to assess whether specific alterations are responsible for the metabolic consequences of OSA.

\section{The lipoxygenase pathway and oxidative stress}

Besides hypoxia, other pathways may contribute to adipocyte dysfunction in obesity. Adipose tissue from high calorie-fed obese mice showed increased expression of lipoxygenases [123], whose products could promote recruitment and activation of macrophages to and within adipose tissue [124]. Knock-out mice for the 12-lipoxygenase gene on a high-calorie diet showed normal TNF- $\alpha$, IL- 6 and adiponectin release; in addition, MCP-1 concentration and the number of macrophages in adipose tissue were normal [123].

Oxidative stress could also play a role. 12-Hydroxyeicosatetraenoic acid (12-HETE) directly controls the increased expression of MCP-1 in macrophages [125], and peroxidation products of HETEs may act as signalling molecules in adipocytes. For instance, 4-hydroxynonenal (4-HNE) exerts pro-inflammatory effects [126], but is normally neutralised by the enzyme glutathione-S-transferase (GST). Mice with a disrupted GST gene gained more weight and accumulated more visceral fat in comparison with control mice, and showed high levels of 4 HNE in tissues [127].

To summarise this section, adipocyte dysfunction in obesity shows both metabolic and pro-inflammatory effects, probably reflecting disturbance of different cellular pathways. Even though knowledge of adipocyte biology has expanded greatly, the many facets of human obesity deserve further investigation. The emerging role of hypoxia and oxidative stress in the pathophysiology of obesity suggest possible interactions with OSA, in particular the activation of mechanisms common to both diseases.

\section{IR AND METS IN OSA}

Increasing severity of OSA in adults is associated with IR and the MetS [36, 37, 128], suggesting a link between OSA, metabolic abnormalities and cardiovascular morbidity and mortality [24, 129-133]. However, the independent role of OSA is still unclear, due to the difficulty in separating the effects of obesity and sleep disordered breathing in human studies.

Characterisation of non-obese adult OSA patients is extremely poor as far as metabolic abnormalities are concerned. No MetS component was found in $\sim 10 \%$ of OSA patients referred for a sleep study; these patients were younger and showed mild-tomoderate OSA compared to all other patients [134]. Absence of metabolic abnormalities might characterise an early stage in the natural history of OSA; alternatively, non-obese OSA patients could represent a distinct phenotype, as proposed for paediatric OSA [34].

However, increased visceral fat may also be a critical factor in non-obese OSA patients, who show increased fat deposition in the abdomen and neck compared to controls [135]. In a Japanese study, neck circumference normalised for height correlated with severity of OSA independent of visceral obesity, especially in 
non-obese subjects [136]. Finally, two studies in the general population recently reported that neck circumference is an independent predictor of cardio-metabolic risk [137] and of both MetS and OSA [138], but sleep studies were not performed in either study.

Clearly, the role of neck fat deposition, which has been extensively studied in the past for its relationship to upper airway dimensions and function, deserves further attention with regard to metabolic problems in OSA. Non-obese OSA patients appear strikingly similar to the phenotype of metabolically obese normal weight subjects [65]. However, to date, no study has assessed cardiovascular risk or outcomes specifically in nonobese OSA patients.

While the association of OSA with increased visceral fat has been known for a long time, the impact of increased subcutaneous fat on OSA and metabolic variables is much less clear. A recent epidemiological study reported that visceral and subcutaneous fat are associated with IR with different strength [139], indicating that more work is needed in this field as clinical cardiovascular outcomes are concerned.

This section briefly discusses some results of human and animal studies on the effects of intermittent hypoxia and OSA on IR and the MetS.

\section{Clinical studies on metabolic abnormalities in OSA}

Clinical and epidemiological studies have shown a progressive worsening of IR or MetS with OSA severity [140-143], even in severe obesity [144], suggesting a causal role of OSA in metabolic derangements. In addition, there is evidence that IR develops during acute exposure to intermittent hypoxia in healthy humans [145]. For further information, the reader is referred to recent reviews on the complex relationship between OSA, glucose metabolism, IR and diabetes [37, 128, 146-151].

The main finding against a role of OSA in altered glucose metabolism is that IR did not improve after CPAP treatment in many studies (see later section). At least part of the variability in results may be accounted for by the sensitivity of methods to detect IR, especially if one considers the peculiar condition of OSA patients who develop respiratory events only at night. For example, acute CPAP application in diabetic patients was found to decrease glucose level variability, as assessed by continuous glucose monitoring [152, 153]. Similarly, glycosylated haemoglobin $(\mathrm{HbA} 1 \mathrm{c})$ could be a sensitive marker of altered glucose metabolism in OSA in patients with [154] or without diabetes [155], or with the MetS [156].

Both leptin and adiponectin have been studied in clinical OSA. Several studies have reported that OSA patients show increased leptin levels compared to body mass index (BMI)-matched controls [157-159]. Some studies found that apnoea/hypopnoea index (AHI) or severity of nocturnal hypoxaemia were independent predictors of plasma leptin concentration [160, 161], while others only confirmed the known association of leptin with obesity but no independent effect of OSA [162-165]. Most studies examined male OSA patients, and sex-related differences are still unknown.

Adiponectin, a metabolically protective adipokine, was found to be decreased in OSA patients compared to controls in proportion to the severity of nocturnal hypoxaemia [166-168], suggesting a possible pathophysiological role of oxidative stress in decreased adiponectin levels in OSA. Other studies, however, reported a closer relationship of low adiponectin levels with obesity than with OSA [165, 169]. A recent study found that, while daytime adiponectin levels correlated with several measures of obesity, the nocturnal fall in circulating adiponectin in OSA patients correlated only with the waist-to-hip ratio, suggesting that adipose tissue distribution may modulate nocturnal adiponectin levels [170].

Case-control studies conducted in MetS patients have provided other pieces of evidence on the effects of OSA on cardiometabolic variables. Compared to patients with MetS but no OSA, patients with MetS and OSA showed: 1) more severe vascular dysfunction [171]; 2) independent associations of OSA with triglyceride and glucose levels, $\mathrm{C}$-reactive protein, uric acid and increased total/high-density lipoprotein (HDL) cholesterol ratio [143]; and 3) higher blood pressure and more severe autonomic dysfunction [172]. Similarly, in hypertensive patients, metabolic abnormalities were the strongest predictors of OSA [173]. It has been proposed that OSA should be considered an additional component of MetS [147, 174]. Recent findings in patients with MetS suggest that OSA may contribute to worse metabolic abnormalities or could represent a marker of MetS severity $[143,171,172]$.

Excessive daytime sleepiness (EDS) is a major symptom of OSA, and could be a marker of OSA severity. Two case-control studies reported that EDS predicts IR in OSA patients [175, 176]; only sleepy patients showed improved insulin sensitivity after CPAP treatment for 3 months [175]. EDS in OSA patients was also found to be associated with type-II diabetes [177]. Other studies, however, did not confirm the association of subjective EDS and a worse metabolic profile in MetS patients [143], in morbidly obese patients [142] or in unselected consecutive OSA patients [134]. Therefore, the significance of EDS as a marker of metabolic abnormalities remains to be ascertained and is the focus of current clinical research.

\section{The intermittent hypoxia mouse model}

To better dissect the mechanisms by which OSA may affect metabolism, a mouse model of intermittent hypoxia has been developed which reproduces some of the effects of human OSA [178]. The main advantage is the possibility to study the response to intermittent hypoxia in lean and fat animals in several tissues by mimicking the intermittent hypoxia pattern that occurs during sleep in humans with OSA. The model also has some disadvantages, such as absence of intermittent hypercapnia [122] and occurrence of sleep disruption, characterised by a deficit in rapid eye movement sleep and decreased delta power during non-rapid eye movement sleep [179]. To overcome these limitations, a model of OSA in rats was recently developed [180] but, to date, has been used only in short-term studies.

In lean mice, acute intermittent hypoxia caused IR [181], but intermittent hypoxia for several days did not [182], possibly because prolonged exposure to intermittent hypoxia was associated with failure to gain weight, which exerted positive effects on insulin sensitivity. In contrast, in mice with genetic or dietinduced obesity, chronic intermittent hypoxia worsened IR [182].

There is no evidence that intermittent hypoxia impairs pancreatic $\beta$-cell function, although $\beta$-cell proliferation and apoptosis 
occurred in mice exposed to intermittent hypoxia [183, 184]. IR during intermittent hypoxia can be mediated via multiple pathways [178]. Among them, activity of the sympathetic nervous system did not appear to play a major role in the effects of acute intermittent hypoxia in lean mice [181]. Acute intermittent hypoxia increased corticosterone release, which could have contributed to IR [181]. The metabolic effects of intermittent hypoxia were larger in obese compared to lean animals, suggesting that isolated intermittent hypoxia may be insufficient to cause significant damage. The results of such experimental studies suggest the hypothesis that OSA could worsen metabolism in obese subjects, while its effects might be limited in non-obese subjects, as recently found in a randomised controlled trial on the effects of CPAP on IR [185]. However, a previous study had reported different results, i.e. insulin sensitivity improved more in non-obese than in obese OSA subjects after CPAP treatment [186]. Therefore, the clinical impact of OSA and its treatment on IR requires further evaluation, especially in lean patients.

To summarise, studies in both OSA patients and animal models indicate that OSA probably contributes to IR, even though its effect may be relatively minor compared to the effect of obesity. However, it should be underlined that human OSA is a multiple component disease, including intermittent hypoxia and sleep fragmentation. The respective contribution of respiratory and polysomnographic parameters to metabolic variables in OSA patients is also a clinically important issue, but could not be addressed in this review.

\section{ECTOPIC FAT AND DYSLIPIDAEMIA}

The metabolic abnormalities of adipocytes in obesity are further amplified by ectopic fat deposition [44]. As storage capacity of adipose tissue is overwhelmed, decreased insulin action in adipose tissue increases lipolysis and release of free fatty acids (FFA) into the circulation, and IR develops in peripheral tissues (the "lipotoxicity" picture) [187-191]. The main targets of FFA in this "overflow hypothesis" [44] are skeletal muscle and the liver (fig. 1).

Obesity increases the amount of perivascular adipose tissue. Previously considered to mainly exert a mechanical support function, perivascular fat has recently been shown to normally exert a vasorelaxant action [192]. Obesity and the associated IR appear to blunt the physiological effect of perivascular fat, causing vascular dysfunction in obese animals [193] and humans [194], with obvious implications for the pathogenesis of cardiovascular disease associated with obesity.

The possibility that ectopic fat deposition may affect pancreatic exocrine function has been recently explored. Pancreatic fat deposition was found in mice fed a high-fat diet and in pathology specimens from patients with type-II diabetes, in the form of adipocyte infiltration and modified lipid content of pancreatic exocrine tissue [195]. In obese subjects, pancreatic fat deposition

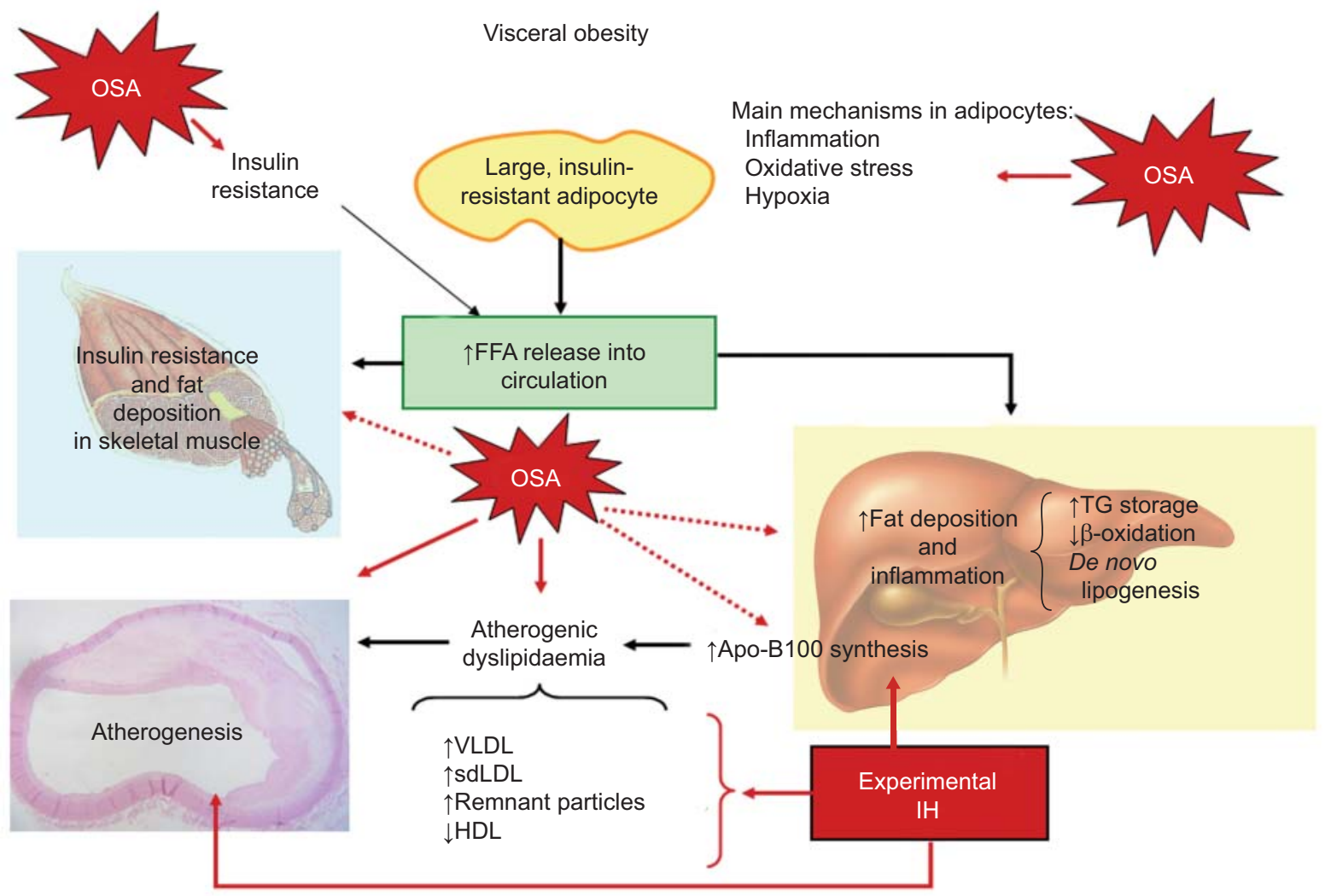

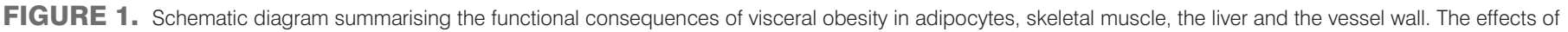

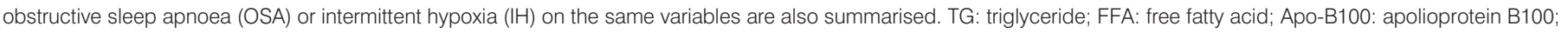
VLDL: very low-density lipoproteins; sdLDL: small dense low-density lipoproteins; HDL: high-density lipoprotein. For further details, refer to the text. 
increased with increasing visceral fat in males [196] but, besides its association with IR, no clear effect of $\beta$-cell function could be demonstrated [197]. Therefore, the pancreas might also be a target in visceral obesity, but more studies are needed to verify the clinical importance of pancreatic fat accumulation on exocrine and endocrine function.

Information on the effects of obesity, OSA and experimental intermittent hypoxia on muscle and liver metabolism is summarised in the following sections.

\section{Skeletal muscle adipose tissue in obesity and OSA}

Obese subjects show increased intra- and intercellular fat deposition in skeletal muscle [190, 198]. By releasing endocrine and metabolic mediators (including TNF- $\alpha$, IL-6, leptin and adiponectin), adipose tissue crosstalks with skeletal muscle, a process that precedes and underlies the development of muscle IR [190]. IR in skeletal muscle is strongly linked to elevated adipose tissue mass [189, 190].

IR in skeletal muscle was initially hypothesised to be secondary to the increased availability of FFA, with subsequent activation of fat oxidation and inhibition of glucose utilisation. This hypothesis predicted intracellular accumulation of glucose-6-phosphate (G6P), due to inhibition of the early steps of glycolysis. However, exposure to FFA was shown to decrease, not increase, intracellular G6P concentration. Therefore, similar to what happens in adipose tissue, impaired insulin-dependent glucose transport plays a major role in skeletal muscle IR [199]. Macrophage infiltration of adipose tissue interspersed between myofibres occurs in obesity [190], and inflammation also exerts negative effects in skeletal muscle [200]. A thorough description of muscle IR is beyond the purpose of this review, but has been given elsewhere [190, 199].

There are no studies on IR in skeletal muscle in OSA patients, but one study in mice subjected to intermittent hypoxia for $9 \mathrm{~h}$ found that glucose utilisation decreased and IR increased in oxidative (soleus) but not in glycolytic (vastus) muscles [181]. Some studies have reported a low exercise capacity in OSA patients, suggesting that OSA may impact on muscle metabolism [201].

\section{Hepatic steatosis and non-alcoholic fatty liver disease Obesity}

Obesity causes intracellular accumulation of lipids in the liver [188, 202], leading to hepatic steatosis which is pathologically defined as presence of fat in $>5 \%$ of hepatocytes. Activation of macrophage-like Kupffer cells in the liver is also common in obesity [203].

Hepatic steatosis is the first step of non-alcoholic fatty liver disease (NAFLD), which includes a spectrum of pathological conditions: steatosis without inflammation; non-alcoholic steatohepatitis (NASH) and liver fibrosis [204-207]. NAFLD increases the risk of developing cryptogenic cirrhosis and hepatocarcinoma [208]. NAFLD is common in obese adults [202, 205, 209-212] and children [213], and is considered as the hepatic manifestation of MetS. NAFLD could develop in steps, with IR and obesity acting as the "first hit" and causing hepatic steatosis [206, 207], and oxidative stress, lipid peroxidation and inflammation probably implicated in the "second hit" [206-208]. Although skeletal muscle is of major importance for insulin-regulated glucose disposal, liver IR will lead to enhanced hepatic glucose production, which may significantly contribute to impaired glucose tolerance and/or hyperglycaemia.

Different mechanisms have been proposed to explain the pathogenesis of NAFDL in obesity [214]. The main view considers hepatic accumulation of fat as a consequence of obesity and IR [199]. Conversely, other studies suggested that fat accumulation in the liver may cause IR independent of visceral fat $[215,216]$. Finally, accumulation of triglycerides in the liver may not be detrimental per se, and could actually exert a protective role by limiting the accumulation of FFA [217].

According to the main view, the liver in obesity is loaded with excess FFA from dietary sources, adipose tissue and de novo synthesis of lipids [202, 218]. Release of FFA from the adipose tissue accounts for a large proportion of liver fat [218], and is favoured by IR at the adipocyte level, as insulin normally promotes lipid storage and inhibits lipolysis and FFA release by adipocytes [219]. While FFA uptake in the liver is increased [215], their $\beta$-oxidation is impaired [202, 220]. Moreover, hyperglycaemia and hyperinsulinaemia enhance de novo lipogenesis in the liver [214]. Therefore, in very simplified terms, liver steatosis in obesity results from disturbance in several steps of FFA/lipid handling.

The cause of the transition from steatosis to steatohepatitis is not completely defined. Inflammation is a major culprit [188, 214], since liver Kupffer cells could play a role similar to that of macrophages in adipose tissue [100]. Indeed, depletion of Kupffer cells in an animal model prevented the development of IR and lipid accumulation in the liver [203].

\section{Obstructive sleep apnoea}

The link between altered metabolism and inflammation in obesity may be amplified in OSA [221]. Increased circulating FFA have been recently reported in patients with OSA without MetS compared to sex-, age- and BMI-matched controls [222] and in patients with chronic heart failure and OSA during sleep [223], suggesting an effect of OSA on lipid metabolism independent of concurrent obesity.

The association of OSA and fatty liver has been recently reviewed [224]. Approximately 50\% of patients with NAFLD refer symptoms of OSA [225], and some case reports suggest that severe OSA may lead to liver injury [226-228]. Noninvasive imaging techniques, such as ultrasound or computed tomography scans, do not currently help to distinguish between simple steatosis and NASH [229-231]. Since liver enzymes are neither sensitive nor specific predictors of NAFLD-related liver damage $[208,209]$, data on NAFLD have mostly been obtained by liver biopsy in obese patients undergoing bariatric surgery [208, 232].

In morbidly obese subjects, the degree of pathological liver abnormalities and/or enzymes increased with OSA severity in some [233-236] but not all studies [237, 238]. Table 1 summarises the main studies on liver function in OSA patients. In subjects with OSA and elevated liver enzymes in the absence of any known liver disease, an AHI $>50$ was associated with more severe hepatic steatosis, necrosis and fibrosis compared to patients with an $\mathrm{AHI} \leqslant 50$, despite similar degree of obesity [239]. Other studies reported an association of intermittent hypoxia during sleep with NASH and liver fibrosis [233, 235, 240] or high serum aminotransferase levels [241]. Severity of 
TABLE 1 Studies on liver dysfunction, obesity and obstructive sleep apnoea (OSA)

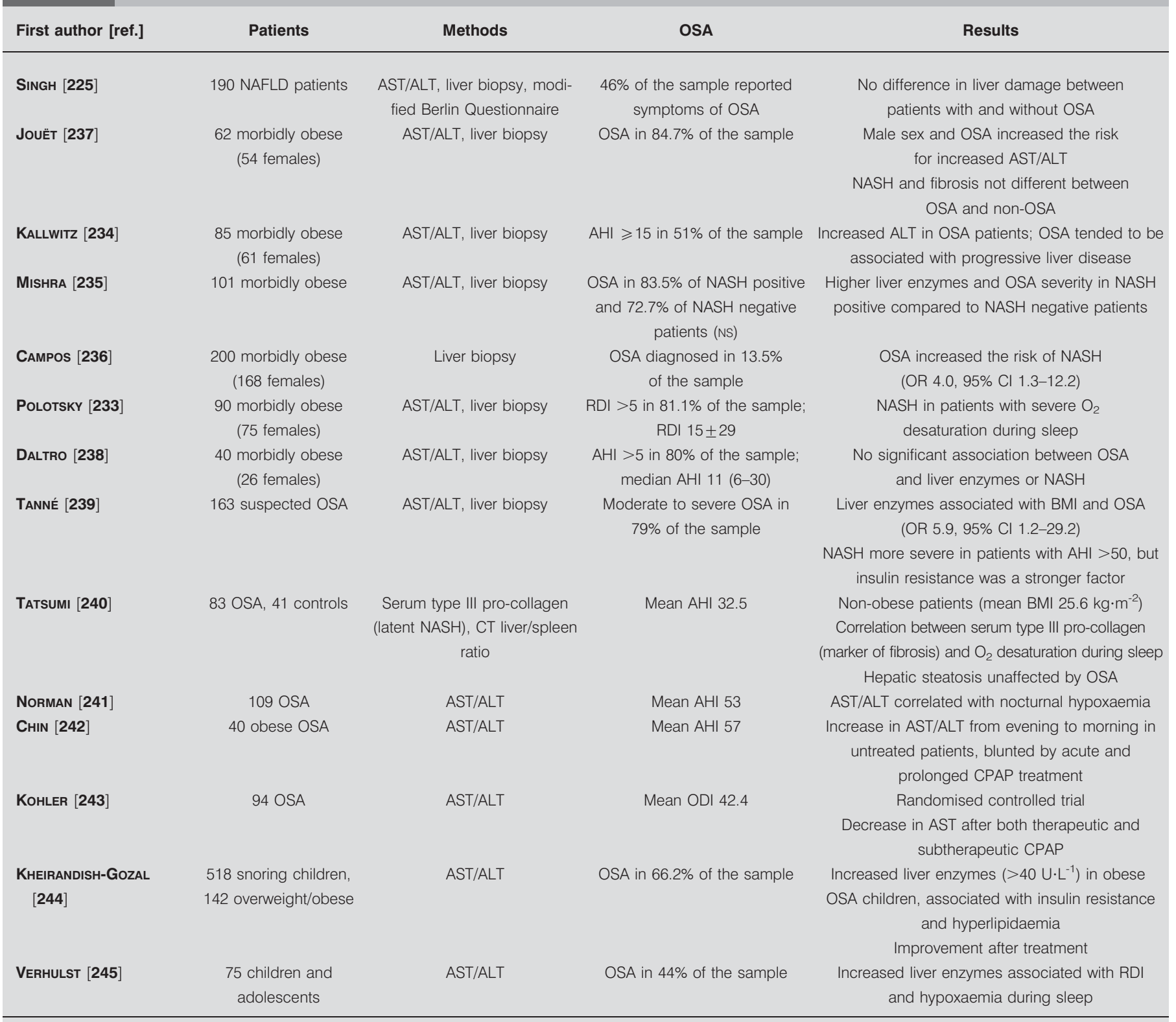

NAFLD: non-alcoholic fatty liver disease; AST: aspartate aminotransferase; ALT: alanine aminotransferase; NASH: non-alcoholic statohepatitis; NS: nonsignificant; RDI: respiratory disturbance index; AHI: apnoea/hypopnoea index; BMI: body mass index; CT: computed tomography; CPAP: continuous positive airway pressure; ODI: oxygen desaturation index.

nocturnal hypoxaemia also correlated with markers of liver dysfunction in non-obese OSA patients [240]. In children, OSA was associated with elevated liver enzyme levels [244, 245], which normalised after adenotonsillectomy [244]. Therefore, some clinical data support the possibility that OSA may worsen liver function.

\section{Intermittent hypoxia in animal models}

In mice fed a high-calorie diet, intermittent hypoxia converted hepatic steatosis to steatohepatitis and liver fibrosis, and caused oxidative stress in the liver by upregulating an important enzyme of oxidative stress, NADPH oxidase [246]. Similarly, exposure of rats to chemically induced hypoxaemia enhanced the development of NASH induced by high-fat diet [247]. In lean mice on regular chow diet, exposure to intermittent hypoxia for 12 weeks caused only minor liver injury [248]. These data suggest that intermittent hypoxia alone is insufficient to cause steatohepatitis but could amplify the damage caused by obesity.

\section{Dyslipidaemia in obesity and OSA}

Obesity, MetS and type-II diabetes are characterised by a specific pattern of plasma lipids, called atherogenic dyslipidaemia [249], which is a powerful cardiovascular risk factor [250-252]. Atherogenic dyslipidaemia is also common in OSA, and a role 
for OSA in worsening dyslipidaemia is suggested by several experimental and clinical studies.

\section{Obesity}

The hallmarks of atherogenic dyslipidaemia associated with obesity and type-II diabetes are: high fasting levels of triglycerides, total cholesterol, and cholesterol associated with very lowand low-density lipoproteins (VLDL and LDL, respectively), and low HDL cholesterol [250]. The liver plays a central role in lipoprotein metabolism [253-255]. Briefly, synthesis, modification and clearance of lipoproteins are complex processes, modulated by insulin at several steps. A major feature of obesity is the overproduction of VLDL, due to increased release of FFA by visceral adipose tissue [254].

Apolipoprotein (Apo)-B is an essential constituent of atherogenic particles, and its plasma level is increasingly used as a clinical marker of atherogenesis [255, 256]. The size of lipoproteins is a crucial determinant of their atherogenetic potential, since small particles remain trapped in the subintimal vascular layer, where they initiate and sustain plaque formation. While the role played by small dense LDL in atherogenesis has been known for a long time [257], recent research has examined the risk linked to remnant lipoproteins, derived from metabolism of triglyceriderich lipoproteins (TRLs) [258].

Obesity is also characterised by low levels of HDL cholesterol, which is considered to exert protective cardiovascular effects. Decreased HDL is, in part, secondary to an exchange of cholesterol triglycerides between HDL and TRL particles, which occurs when TRL levels increase [254]. Hepatic and endothelial lipases have also been shown to modulate HDL levels in obesity [254].

\section{Obstructive sleep apnoea}

The association between OSA and dyslipidaemia has been explored in several studies. In a large community-based sample (the Sleep Heart Health Study), OSA severity correlated with fasting total cholesterol levels independent of BMI [259]. In elderly subjects, OSA was associated with low HDL cholesterol levels independent of age and BMI [260].

In a case-control study, patients with OSA had higher total and LDL cholesterol levels compared to controls matched for age, BMI and smoking status [261]. Increased Apo-B levels have been found in adult [262] and paediatric [263] OSA patients, and Apo-B decreased after effective OSA treatment [262-264].

OSA patients show decreased levels of lipoprotein lipase [265] and pro-atherogenic dyslipidaemia [142, 266-268]. Severity of nocturnal hypoxaemia predicted increased liver levels of stearoyl coenzyme A desaturase (SCD-1), an enzyme involved in triglyceride biosynthesis and lipopotein secretion, in obese OSA patients [233]. In contrast, other studies found similar plasma lipids in patients with OSA and controls [171, 269-271]. HDL dysfunction has also been found in OSA [270]. Therefore, OSA appears to be associated with dyslipidaemia, but data are still insufficient to confirm a causal relationship.

\section{Intermittent hypoxia in animal models}

In lean mice, chronic intermittent hypoxia increased serum total cholesterol, triglycerides, VLDL cholesterol, LDL cholesterol and lipid liver content [272-274] proportionally to the severity of the hypoxic stimulus [274]. In obese $o b / o b$ mice, chronic intermittent hypoxia exacerbated dyslipidaemia, hepatic steatosis and IR [182, 272]. While isolated chronic intermittent hypoxia was not sufficient to cause atherosclerosis, it greatly potentiated the proatherogenic effects of a high-cholesterol diet [275].

Studies in mice have identified some steps of hepatic lipid biosynthesis which are affected by intermittent hypoxia [214, 276]. Intermittent hypoxia increases hepatic levels of the transcription factor sterol regulatory element binding protein (SREBP)-1 and of SCD-1 $[272,273,277]$. Dyslipidaemia and hepatic steatosis in mice exposed to chronic intermittent hypoxia were associated with upregulation of SCD-1 [271-275, 278], while depletion of SCD-1 reversed hyperlipidaemia [277]. Thus, chronic intermittent hypoxia may induce metabolic dysfunction via SCD-1.

The mechanisms by which intermittent hypoxia impacts on hepatic lipid biosynthesis are poorly understood. Hypoxic activation of HIF- $1 \alpha$ may play a role, since mice with partial deficiency of HIF- $1 \alpha$ exposed to intermittent hypoxia showed attenuated hyperlipidaemia, IR, hepatic steatosis and SCD-1 induction [279]. However, other pathways may also be involved. First, acute hypoxia induces lipolysis, possibly via sympathetic activation [280]. Secondly, hypoxia may suppress $\beta$-oxidation of fatty acids [281]. Finally, intermittent hypoxia decreases the activity of lipoprotein lipase in adipose tissue [282], which plays a primary role in the hydrolysis of triglycerides in circulating chilomicrons and VLDL [283, 284].

As a summary of this section, figure 1 schematically reports the metabolic abnormalities found in visceral obesity and OSA, and highlights points of possible detrimental synergies of both conditions.

\section{THE METABOLIC EFFECTS OF SLEEP LOSS}

Sleep loss may play a role in the pathogenesis of obesity and metabolic abnormalities, as suggested by epidemiological and mechanistic studies $[14,15]$. An association of self-reported short sleep and/or sleep disruption with MetS has been found in the general population [285-287] and shift workers [288, 289]. Short sleep duration may increase the risk of incident diabetes [290, 291] and stroke [292]. Some studies suggest that sleep loss may contribute to the pathogenesis of cardiovascular disease in shift workers [293-295].

Cross-sectional epidemiological data in adults and children have shown an association between obesity and self-reported short sleep duration and/or poor quality of sleep [14, 296-298]. A negative linear association between baseline habitual sleep duration and later obesity has been demonstrated by prospective longitudinal data in children [298] but not in adults [299]. However, there are no experimental data in children or adults demonstrating that shortened sleep and/or poor sleep quality are causally related to the increased prevalence of obesity. Furthermore, in mice, chronic sleep restriction induced a catabolic state and weight loss despite increased feeding [300]. Reduced sleep duration (at least in the short-term) may increase the risk of weight gain by altering the regulation of appetite and by reducing insulin sensitivity [301-303]. Slow wave sleep (SWS) appears to play a protective role [304], in agreement with crosssectional population data showing an inverse association between the amount of SWS and BMI. In addition, even a modest sleep restriction is associated with increased release of inflammatory cytokines in healthy young adults [305]. Finally, 
circadian rhythms are increasingly studied with special attention to the role of peripheral clock genes in obesity, diabetes and cardiovascular disease [306-310].

Little is known about the effects of sleep fragmentation, as it occurs in OSA patients, on metabolic variables. A recent study showed decreased insulin sensitivity and increased sympathetic activation in normal subjects after acute sleep fragmentation [311].

In the future, studies will need to closely examine compartmentspecific adipose tissue (especially visceral fat) under conditions of sleep restriction and/or disruption. Experimental manipulation of sleep requires intensive sampling during the day and the night under conditions of constant routine. The role of OSA-associated sleep disruption in promoting visceral obesity is still an open question.

\section{EFFECTS OF TREATMENT FOR OBESITY AND OSA}

The aim of this section is to briefly discuss some aspects of obesity and OSA with regard to treatment. In particular, the major problem of weight loss by pharmacological treatment or bariatric surgery is addressed in obese and OSA patients, as well as the changes in metabolic variables observed after CPAP treatment.

\section{Therapeutic strategies in obesity and the metabolic impact of weight loss}

Interventions aiming at correcting visceral adipocyte dysfunction may positively modulate the clinical phenotype and cardiometabolic outcomes of MetS patients [312]. Non-pharmacological approaches, such as diet to reduce calorie intake and exercise to increase energy expenditure, are the most effective interventions to improve metabolism and prevent type-II diabetes in individuals at risk $[313,314]$.

Other modalities of weight loss, such as bariatric surgery or medications, may have more success in the long-term than diet alone, as summarised in a recent review [315]. Laparoscopic gastric banding in severe obesity is a safe and effective method to achieve long-term weight reduction [316-318]. The Swedish Obesity Study has shown long-term weight loss and decreased 10 -yr mortality in severely obese patients randomised to bariatric surgery compared to those undergoing conventional dietary treatment [319].

A comprehensive discussion of the treatment of obesity is beyond the scope of this review. It is worth noting that the development of new drugs to improve insulin sensitivity and reduce body weight is a major continuing challenge for the pharmaceutical industry. For example, drugs that improve insulin action are available (i.e. specific agonists of the peroxisome proliferator activated receptor- $\gamma$ nuclear receptor), but their usefulness in obese patients is limited since they may also promote weight gain [312]. Thiazolidinediones are also a class of medications with severe side-effects. In addition, the development of drugs for obesity has been, until now, hampered by significant side-effects, as recently shown by the experience with rimonabant, a selective antagonist of endocannabinoid CB1 receptor. Endocannabinoid CB1 receptors initially appeared to be a good target for treatment, since they are highly expressed in regions of the brain involved in feeding and energy regulation, but also in adipose tissue, the gastrointestinal tract, liver and skeletal muscle [320]. In phase-III clinical trials, rimonabant caused weight loss and improved the metabolic profile [312], but had to be withdrawn from the market because of major psychiatric side-effects [321]. Another recent target for obesity treatment is represented by the incretin system [322]. The results are promising for the treatment of obese patients, since incretin mimetics were found to reduce overall body fat with prominent effects on visceral adipose tissue [323, 324].

Inflammation in visceral obesity is another potential intervention target, and salicylate derivatives are currently under intense investigation [325-328]. However, efficacy of new drugs needs to be tested not only for reduction of body weight, but also for prevention of cardiovascular events in the long term. In addition, new drugs should be specifically studied in patients of different ages, given the significant prevalence of obesity in young and old subjects [329].

\section{Metabolic impact of CPAP treatment in OSA}

CPAP intervention studies can provide information on whether specific health effects in obese patients can be modified by reversal of OSA. In general, analysis of the effects of CPAP is complicated by the variable compliance and adherence to treatment by OSA patients. CPAP treatment does not promote weight loss [330], and did not clearly affect diabetes [331] or other metabolic disorders [37]. The majority of recent studies, including randomised controlled trials [332-334], showed no effect of CPAP treatment on metabolic variables despite improvements in sleepiness and blood pressure, as recently summarised [37, 128, $150,151,335,336]$. However, a recent randomised controlled trial in Chinese male OSA patients without significant comorbidities reported improved insulin sensitivity in the effective CPAP group after 1 week of treatment, which was maintained at 3 months only in overweight/obese patients [185].

Circulating leptin decreased after CPAP treatment [157, 337], especially in non-obese [157, 337] and CPAP-compliant [339, 340] patients. CPAP treatment also reversed low serum adiponectin levels in obese OSA patients [166, 167], even though IR was unaffected [167]. These data are in agreement with the experimental findings that both continuous and intermittent hypoxia in vitro inhibit adiponectin production or secretion by adipocytes $[37,89,90,114]$, but firm evidence is still missing, given the negative result of a randomised controlled trial [334].

A similar uncertainty exists with regard to the effects of CPAP treatment on liver dysfunction. In an observational study, CPAP treatment for OSA for a single night slightly, but significantly, decreased serum alanine aminotransferase and aspartate aminotransferase levels [242]. In contrast, a randomised controlled trial found no difference in liver enzymes after effective or sham CPAP treatment [243]. Whether CPAP treatment for OSA affects liver pathology, i.e. the amount of fat deposition and NAFLD severity, is currently unknown.

Several non-randomised and randomised studies have examined the effect of OSA treatment on plasma lipids. CHIN and COworkers [341, 342] first showed that CPAP treatment decreased LDL cholesterol and increased HDL cholesterol levels. Positive effects of CPAP on lipids were reported in three non-randomised studies [262, 264, 337]. A large randomised controlled trial found decreased plasma cholesterol levels after therapeutic but not after sub-therapeutic CPAP for 1 month [343]. Three other randomised studies showed no effect of CPAP, but they included small numbers of subjects [262, 332, 337]. Therefore, current evidence suggests that CPAP treatment may decrease total and LDL 
cholesterol levels. Unfortunately, none of the available studies stratified patients for obesity.

\section{Metabolic impact of weight loss in OSA}

Although changes in weight were associated with changes in OSA severity in both population and clinic-based studies [28-31], weight loss research for OSA has been hampered with doubts about the long-term effectiveness of weight loss as the only treatment in OSA. It is still unknown whether OSA patients could lose weight in the short or long term, and by what method this might be best achieved [344]. A recent randomised controlled trial of diet-induced weight loss for mild OSA reported positive results [345], but mild OSA may carry limited or no morbidity. In moderate-to-severe OSA, a therapeutic approach combining CPAP with diet to reduce weight might be more appropriate, as suggested by two recent randomised controlled trials in obese diabetic [346] or non-diabetic [347] OSA patients. Data after 1-yr of follow-up suggest that long-term maintenance of weight after initial very low energy diet in obese OSA patients is associated with persistent improvement of OSA [348]. Other studies reported less optimistic results after a 2-yr follow-up [349].

Bariatric surgery has also been used in OSA patients. In the Swedish Obesity Study cohort, prevalence of OSA-related symptoms at 2 yrs of follow-up decreased proportionally to weight loss [350]. According to a meta-analysis conducted in 2004 , OSA resolved in $85 \%$ of the patients after bariatric surgery [350], as confirmed by studies including polysomnographic assessment [351-353].

As for use of medications to treat obesity, the effects of sibutramine have been recently assessed in obese OSA patients. Sibutramine did not affect sleep [354], and weight loss was associated with improved AHI and daytime sleepiness over a 6month period [355]. The metabolic profile improved in obese OSA patients treated with sibutramine, low-calorie diet and exercise for 6 months [356]. Another study compared the effects of sibutramine to those of CPAP in patients who had been allowed to choose between the two treatments [357]. Sibutramine treatment caused a 5-kg weight loss over $1 \mathrm{yr}$ and positively modified oxygen saturation during sleep, but did not affect AHI or cardiovascular variables. Conversely, CPAP-treated patients improved their respiratory variables during sleep and daytime blood pressure but did not lose weight [357]. Unfortunately, the results of these studies are not going to impact on the clinical management of OSA patients as sibutramine was withdrawn in Europe in early 2010 due to increased cardiovascular events associated with prolonged administration of the drug [358].

Overall, these studies underline the need for individualised treatment of obesity in OSA patients. Life-long adherence to CPAP treatment is a problem in OSA treatment [359], justifying additional pharmacological approaches. It is likely that OSA treatment and metabolic risk management, possibly integrated in the same sleep centre, may be necessary to obtain optimal results, but evidence-based management strategies are still missing.

\section{OBESITY AND OSA IN CHILDREN}

Obesity and MetS in children have been increasingly studied in the past decade. Genetic defects, sedentary lifestyle and unhealthy food habits are considered the main culprits of paediatric obesity [360] and the increasing prevalence of type-II diabetes in the young population [361]. Clinically, the immediate and long-term effects of childhood obesity are strikingly similar to those of adult obesity [360]. There is evidence that cardiovascular lesions develop in obese children [362], raising concerns about the long-term impact of childhood obesity on health.

Prevalence of OSA in children is expected to increase due to the rise in obesity [18-20]. Besides its immediate effects (snoring and daytime symptoms), paediatric OSA may influence the natural history of sleep disordered breathing in adulthood [363], including metabolic dysfunction. However, not every child with OSA will manifest adverse consequences, suggesting modulation by genetic and environmental factors [364].

OSA and obesity probably interact at the level of upper airways. Obese children with OSA demonstrated larger tonsils and adenoids compared to controls [365,366], and a higher risk of residual OSA after adenotonsillectomy [365, 367]. However, upper airway closure may occur in obese children for a smaller degree of tonsil and adenoid enlargement than in non-obese children [365]. The relative contribution of (central) obesity and adenotonsillar hypertrophy remains to be elucidated and may differ between young children, in whom adenotonsillar hypertrophy might play a major role, and adolescents, who show a predominant role of obesity [368]. Recent studies have tried to address the impact of fat distribution and neck anatomy in a casecontrol study of obese children with and without OSA [369], but more studies are needed before drawing any conclusion on this topic. It should be pointed out that hereditable factors influencing craniofacial structures represent important predisposing conditions to develop upper airway obstruction, together with the acquired factors of adenotonsillar hypertrophy and obesity [370].

Similar to adults, obese children and adolescents often develop MetS [371-375], which appears linked to visceral obesity and ectopic fat deposition [376], secondary to excess calorie intake and reduced physical activity. While obesity is known to increase the risk for OSA, it is unclear whether OSA in children is directly involved in the pathogenesis of MetS. In contrast to adults, the paediatric population is relatively free from prolonged exposure to cardio-metabolic risk factors, and childhood OSA causes a lesser degree of oxygen desaturation than adult OSA, resulting in milder intermittent hypoxaemia compared to adult patients. OSA-associated nocturnal hypoxaemia in children independently predicted MetS and glucose intolerance [377-379], and prevalence of MetS increased with increasing severity of OSA [380-382], together with markers of inflammation [382], arterial alterations [383], and excessive daytime sleepiness [382, 384]. In non-obese children, the HDL cholesterol level was recently found to be inversely correlated with OSA severity [385]. Conversely, other studies have suggested that IR in children with OSA is associated with obesity rather than OSA [386-388].

A similar degree of uncertainty surrounds liver dysfunction. Two studies reported increased elevated serum aminotransferase levels in obese children with OSA, suggesting that OSA could act as a "second hit" in the development of NAFLD in children [244, 245]. Increased leptin levels have been reported in children with OSA, in the absence of changes in either adiponectin or resistin [389]. Other studies suggested that adiponectin is a sensitive marker of OSA in obese pubertal children [387] or found a predominant effect of obesity on adipokine levels [390]. The 
exact pathogenesis and long-term consequences of early perturbations in metabolism by paediatric OSA warrant urgent research efforts.

\section{Effects of treatment of paediatric OSA}

Therapeutic interventions in children should be aimed at correcting both sleep apnoea and concomitant obesity if present. There is no agreement in the criteria to define the success rate of treatment in paediatric OSA, making it hard to compare the results of available studies [391].

The results of adenotonsillectomy are conflicting. Adenotonsillectomy carries a low success rate [25]. In addition, BMI often increases post-operatively, due to increased appetite, decreased nocturnal energy expenditure and decreased total motor activity [392]. One study using a pre/post-surgery design to assess the effect of OSA on IR in non-obese and obese children found that OSA was clearly associated with IR in obese children only. Plasma lipids markedly decrease in obese patients with resolution of OSA, while they showed a minor improvement in patients with residual OSA post-surgery [261]. In another study, lipid profiles, C-reactive protein and Apo-B significantly improved after adenotonsillectomy in both obese and non-obese children [389]. Other studies failed to show any effect of adenotonsillectomy on fasting insulin or the HOMA (homeostatic model assessment) index, or found that the metabolic profile worsened after surgery due to increased BMI [393], or were insufficiently powered to detect differences between subsets of obese children after surgery [394]. As for liver dysfunction, serum aminotransferase levels decreased in the majority of obese OSA children after adenotonsillectomy [244], but further study is needed to confirm a cause-effect relationship between OSA and NAFLD [395].

Experience with CPAP in children is limited, and the problem of long-term compliance to treatment may be as crucial as in adults. A single study in children found a slight decrease in leptin after CPAP treatment, while insulin sensitivity, BMI and norepinephrine levels were unaffected [396]. Weight loss is a promising alternative [391], but long-term compliance to weight loss is also a relevant problem in children.

\section{FUTURE RESEARCH DIRECTIONS}

Several important areas can be identified for future research. We have started to understand some mechanisms by which OSA may worsen metabolism, and studies in mice have provided a large amount of data on the effects of chronic intermittent hypoxia. However, the effects of decreased or disrupted sleep on metabolism remain incompletely defined in both obesity and OSA. Interestingly, sleep loss may not only promote weight gain, but could also diminish fat loss during a low-calorie diet, as recently found in obese humans [301].

Studies on the effects of hypoxia on adipocyte function face some methodological problem, since in vitro exposure to room air actually represents a condition of hyperoxia compared to the value of tissue $\mathrm{PO}_{2}$ measured in live animals $[114,115]$ and humans [112]. Testing the effects of intermittent hypoxia in vitro on adipose tissue is problematic, due to the technical difficulty of controlling the rate of gas diffusion in cell cultures. This problem can be partly overcome by reducing the number of intermittent hypoxia cycles per minute, in order to obtain measurable oscillations in oxygen levels in the supernatant to which the cells are exposed.
Knowledge on adipose tissue function in OSA patients is still insufficient, and the biology of adipocytes from different fat depots (visceral and subcutaneous) in obese and non-obese OSA patients has not been studied. The pattern of adipokines in OSA is incompletely defined, as well as their interaction with inflammation, which plays such an important role in both OSA and obesity.

The role of OSA and obesity in causing metabolic abnormalities in children is incompletely understood. Given the partial success of adenotonsillectomy, sleep studies and metabolic assessment should be performed in children after surgery in order to evaluate the need for further treatment. Randomised controlled studies are needed to identify the best therapeutic strategy in paediatric OSA according to the specific OSA phenotype. In addition, longitudinal studies to explore the long-term consequences of OSA in children are warranted.

A comprehensive approach, aimed at abolishing OSA but also at attaining long-term reduction in body weight, is desirable in both adults and children with OSA. In patients undergoing bariatric surgery, resolution or improvement of obesity improved OSA, especially in males. However, patients undergoing bariatric surgery may not be representative of the whole OSA population because of usual predominance of morbidly obese females. Bariatric surgery has provided important data on liver function in OSA, and remains a good opportunity for metabolic studies at the time of the intervention. Moreover, liver biopsies are easily obtained at the time of bariatric surgery, but collecting them during follow-up or in patients treated with CPAP is ethically problematic. Hopefully, improved noninvasive means of diagnosis of NAFLD will help to improve liver assessment in OSA patients.

From a clinical point of view, new models of integrated care, possibly in the same centre, are needed for treatment of obese OSA patients. A multidisciplinary approach seems necessary for both adult and paediatric patients in order to provide effective treatment and prevent metabolic and cardiovascular consequences of both obesity and OSA.

\section{STATEMENT OF INTEREST}

None declared.

\section{ACKNOWLEDGEMENTS}

This review is based on the data presented during the joint European Respiratory Society EU COST actions B26 and BM0602 research seminar held in Palermo, Italy in October 2009. The participants of the seminar were as follows: M.R Bonsignore (Chair of the Seminar; Palermo, Italy), J. Eckel (Co-Chair of the Seminar, Chair of COST Action BM0602; Düsseldorf, Germany), W.T. McNicholas (Chair of COST Action B26; Dublin, Ireland), L. Kheirandish-Gozal (Sections of Pediatric Sleep Medicine and Pediatric Pulmonology, Dept of Pediatrics, Comer Children's Hospital, Pritzker School of Medicine, University of Chicago, Chicago, IL, USA), F. Giorgino (Dept of Emergency and Organ Transplantation, Section of Internal Medicine, Endocrinology, Andrology and Metabolic Diseases, University of Bari Aldo Moro, Bari, Italy), T. Gislason (National University Hospital of Iceland, Reykjavik, Iceland), R.R. Grunstein and C.L. Phillips (Sleep and Circadian Research Group, Woolcock Institute of Medical Research, Sydney, New South Wales, Australia), V.S. Polotsky (Division of Pulmonary and Critical Care Medicine, Johns Hopkins University, Baltimore, MD, USA), R. Riha (Dept of Sleep Medicine, Royal Infirmary Edinburgh, Edinburgh, UK), S. Sasson (Institute for Drug Research, Dept of Pharmacology, The Hebrew 
University Faculty of Medicine, Jerusalem, Israel), P. Trayhurn (Obesity Biology Research Unit, School of Clinical Sciences, University of Liverpool, Liverpool, UK) and S. Verhulst (Dept of Pediatrics, Antwerp University Hospital, Edegem, Belgium).

\section{REFERENCES}

1 Jensen MK, Chiuve SE, Rimm EB, et al. Obesity, behavioral lifestyle factors, and risk of acute coronary events. Circulation 2008; 117: 3062-3069.

2 Rocha VZ, Libby P. Obesity, inflammation, and atherosclerosis. Nat Rev Cardiol 2009; 6: 399-409.

3 Pischon T, Boeing H, Hoffmann K, et al. General and abdominal adiposity and risk of death in Europe. N Engl J Med 2008; 359: 2105-2120.

4 Ogden CL, Carroll MD, Flegal KM. High body mass index for age among US children and adolescents, 2003-2006. J Am Med Assoc 2008; 299: 2401-2405.

5 Jackson-Leach R, Lobstein T. Estimated burden of paediatric obesity and co-morbidities in Europe. Part 1. The increase in the prevalence of child obesity in Europe is itself increasing. Int J Pediatr Obes 2006; 1: 26-32.

6 Steinberger J, Moran A, Hong CP, et al. Adiposity in childhood predicts obesity and insulin resistance in young adulthood. J Pediatr 2001; 138: 469-473.

7 Cali AM, Caprio S. Obesity in children and adolescents. J Clin Endocrinol Metab 2008; 93: Suppl. 1, s31-s36.

8 Trayhurn P, Wood S. Adipokines: inflammation and the pleiotropic role of white adipose tissue. Br J Nutr 2004; 92: 347-355.

9 Hotamisligil GS. Inflammation and metabolic disorders. Nature 2006; 444: 860-867.

10 Hotamisligil GS, Erbay E. Nutrient sensing and inflammation in metabolic diseases. Nat Rev Immunol 2008; 8: 923-934.

11 Einstein FH, Atzmon G, Yang XM, et al. Differential responses of visceral and subcutaneous fat depots to nutrients. Diabetes 2005; 54 : 672-678.

12 Trayhurn P, Wang B, Wood IS. Hypoxia in adipose tissue: a basis for the dysregulation of tissue function in obesity? Br J Nutr 2008; 100: 227-235.

13 Yang L, Hotamisligil GS. Stressing the brain, fattening the body. Cell 2008; 135: 20-22.

14 Cappuccio FP, Taggart FM, Kandala NB, et al. Meta-analysis of short sleep duration and obesity in children and adults. Sleep 2008; 31: 619-626.

15 Marshall NS, Glozier N, Grunstein RR. Is sleep duration related to obesity? A critical review of the epidemiological evidence. Sleep Med Rev 2008; 12: 289-298.

16 Young T, Peppard PE, Taheri S. Excess weight and sleepdisordered breathing. J Appl Physiol 2005; 99: 1592-1599.

17 Li C, Ford ES, Zhao G, et al. Prevalence of self-reported clinically diagnosed sleep apnea according to obesity status in men and women: National Health and Nutrition Examination Survey, 2005-2006. Prev Med 2010; 51: 18-23.

18 Kaditis AG, Alexopoulos EI, Hatzi F, et al. Adiposity in relation to age as predictor of severity of sleep apnea in children with snoring. Sleep Breath 2008; 12: 25-31.

19 Tauman R, Gozal D. Obesity and obstructive sleep apnea in children. Paediatr Respir Rev 2006; 7: 247-259.

20 Redline S, Tishler PV, Schluchter M, et al. Risk factors for sleepdisordered breathing in children. Association with obesity, race, and respiratory problems. Am J Respir Crit Care Med 1999; 159: 1527-1532.

21 Eckert DJ, Malhotra A. Pathophysiology of adult obstructive sleep apnea. Proc Am Thorac Soc 2008; 5: 144-153.

22 Levy P, Pepin JL, Arnaud C, et al. Intermittent hypoxia and sleep-disordered breathing: current concepts and perspectives. Eur Respir J 2008; 32: 1082-1095.
23 Bianchi MT, Cash SS, Mietus J, et al. Obstructive sleep apnea alters sleep stage transition dynamics. PLoS ONE 2010; 5: e11356.

24 Marin JM, Carrizo SJ, Vicente E, et al. Long-term cardiovascular outcomes in men with obstructive sleep apnoea-hypopnoea with or without treatment with continuous positive airway pressure an observational study. Lancet 2005; 365: 1046-1053.

25 Costa DJ, Mitchell R. Adenotonsillectomy for obstructive sleep apnea in obese children: a meta-analysis. Otolaryngol Head Neck Surg 2009; 140: 455-460.

26 Bhattacharjee R, Kheirandish-Gozal L, Mitchell RB, et al. Adenotonsillectomy outcomes in treatment of obstructive sleep apnea in children. A multicenter retrospective study. Am J Respir Crit Care Med 2010; 182: 676-683.

27 Phillips BG, Hisel TM, Kato M, et al. Recent weight gain in patients with newly diagnosed obstructive sleep apnea. J Hypertens 1999; 17: 1297-1300.

28 Newman AB, Foster G, Givelber R, et al. Progression and regression of sleep-disordered breathing with changes in weight. Arch Intern Med 2005; 165: 2408-2413.

29 Peppard PE, Young T, Palta M, et al. Longitudinal study of moderate weight change and sleep-disordered breathing. J Am Med Assoc 2000; 284: 3015-3021.

30 Grunstein RR, Wilcox I, Yang TS, et al. Snoring and sleep apnoea in men: association with central obesity and hypertension. Int J Obes Relat Metab Disord 1993; 17: 533-540.

31 Welch KC, Foster GD, Ritter CT, et al. A novel volumetric magnetic resonance imaging paradigm to study upper airway anatomy. Sleep 2002; 25: 532-542.

32 Katsuki A, Sumida Y, Urakawa $\mathrm{H}$, et al. Increased visceral fat and serum levels of triglyceride are associated with insulin resistance in Japanese metabolically obese, normal weight subjects with normal glucose tolerance. Diabetes Care 2003; 26: 2341-2344.

33 Geer EB, Shen W. Gender differences in insulin resistance, body composition, and energy balance. Gend Med 2009; 6: 60-75.

34 Sans Capdevila O, Kheirandish-Gozal L, Dayyat E, et al. Pediatric obstructive sleep apnea: complications, management, and longterm outcomes. Proc Am Thorac Soc 2008; 5: 274-282.

35 Bonuck K, Parikh S, Bassila M. Growth failure and sleep disordered breathing: a review of the literature. Int J Pediatr Otorhinolaryngol 2006; 70: 769-778.

36 Bonsignore MR, Eckel J. Metabolic aspects of obstructive sleep apnoea syndrome. Eur Respir Rev 2009; 18: 113-124.

37 Lévy P, Bonsignore MR, Eckel J. Sleep, sleep-disordered breathing and metabolic consequences. Eur Respir J 2009; 34: 243-260.

38 Yin J, Gao Z, He Q, et al. Role of hypoxia in obesity-induced disorders of glucose and lipid metabolism in adipose tissue. Am J Physiol Endocrinol Metab 2009; 296: E333-E342.

39 Lavie L, Lavie P. Molecular mechanisms of cardiovascular disease in OSAHS: the oxidative stress link. Eur Respir J 2009; 33: $1467-1484$.

40 Wolk R, Somers VK. Obesity-related cardiovascular disease: implications of obstructive sleep apnea. Diabetes Obes Metab 2006; 8: 250-260.

41 Kent BD, Ryan S, McNicholas WT. The genetics of obstructive sleep apnoea. Curr Opin Pulm Med 2010; 16: 536-542.

42 Riha RL. Genetic aspects of the obstructive sleep apnoea/ hypopnoea syndrome - is there a common link with obesity? Respiration 2009; 78: 5-17.

43 Riha RL, Gislasson T, Diefenbach K. The phenotype and genotype of adult obstructive sleep apnoea/hypopnoea syndrome. Eur Respir J 2009; 33: 646-655.

44 Lee D-E, Kehlenbrik S, Lee H, et al. Getting the message across: mechanisms of physiological cross talk by adipose tissue. Am J Physiol Endocrinol Metab 2009; 296: 1210-1229.

45 Rosen ED, Spiegelman BM. Adipocytes as regulators of energy balance and glucose homeostasis. Nature 2006; 444: 847-853. 
46 Trayhurn P, Bing C, Wood IS. Adipose tissue and adipokines: energy regulation from the human perspective. J Nutr 2006; 136 Suppl. 7, 1935S-1939S.

47 Ouchi N, Parker JL, Lugus JJ, et al. Adipokines in inflammation and metabolic disease. Nature Rev Immunol 2011; 11: 85-97.

48 DiGirolamo M, Fine JB, Tagra $\mathrm{K}$, et al. Qualitative regional differences in adipose tissue growth and cellularity in male Wistar rats fed ad libitum. Am J Physiol Regul Integr Comp Physiol 1998; 274: R1460-R1467.

49 Garaulet M, Hernandez-Morante JJ, Lujan J, et al. Relationship between fat cell size and number and fatty acid composition in adipose tissue from different fat depots in overweight/obese humans. Int J Obes 2006; 30: 899-905.

50 Jo J, Gavrilova O, Pack S, et al. Hypertrophy and/or hyperplasia: dynamics of adipose tissue growth. PLoS Comput Biol 2009; 5 : e1000324.

51 Bowers RR, Festuccia WT, Song CK, et al. Sympathetic innervation of white adipose tissue and its regulation of fat cell number. Am J Physiol Regul Integr Comp Physiol 2004; 286: R1167-R1175.

52 Guo K, Mogen J, Struzzi S, et al. Preadipocyte transplantation: an in vivo study of direct leptin signaling on adipocyte morphogenesis and cell size. Am J Physiol Regul Integr Comp Physiol 2009; 296: R1339-R1347.

53 Kloting N, Fasshauer M, Dietrich A, et al. Insulin-sensitive obesity. Am J Physiol Endocrinol Metab 2010; 299: E506-E515.

54 Cinti S. Transdifferentiation properties of adipocytes. Am J Physiol Endocrinol Metab 2009; 297: E977-E986.

55 Nedergaard J, Bengtsson T, Cannon B. Unexpected evidence for active brown adipose tissue in adult humans. Am J Physiol Endocrinol Metab 2007; 293: E444-E452.

56 Stephens M, Ludgate M, Rees A. Brown fat and obesity: the next big thing? Clin Endocrinol 2011; 74: 661-670.

57 Taksali SE, Caprio S, Dziura J, et al. High visceral and low abdominal subcutaneous fat stores in the obese adolescent: a determinant of an adverse metabolic phenotype. Diabetes 2008; 57: 367-371.

58 Sattar N, Gaw A, Scherbakova O, et al. Metabolic syndrome with and without C-reactive protein as a predictor of coronary heart disease and diabetes in the West of Scotland Coronary Prevention Study. Circulation 2003; 108: 414-419.

59 Alberti KG, Zimmet P, Shaw J. The metabolic syndrome - a new worldwide definition. Lancet 2005; 366: 1059-1062.

60 Bays HE, Gonzales-Campoy JM, Bray GA, et al. Pathogenic potential of adipose tissue and metabolic consequences of adipocyte hypertrophy and increased visceral adiposity. Expert Rev Cardiovasc Ther 2008; 6: 343-368.

61 Walker GE, Verti B, Marzullo P, et al. Deep subcutaneous adipose tissue: a distinct abdominal adipose depot. Obesity 2007; 15: 1933-1943.

62 Ouwens DM, Sell H, Greulich S, et al. The role of epicardial and perivascular adipose tissue in the pathophysiology of cardiovascular disease. J Cell Mol Med 2010; 14: 2223-2234.

63 Grundy SM, Cleeman JI, Daniels SR, et al. Diagnosis and management of the metabolic syndrome: an American Heart Association/National Heart, Lung, and Blood Institute Scientific Statement. Circulation 2005; 112: 2735-2752.

64 Simmons RK, Alberti KG, Gale EA, et al. The metabolic syndrome: useful concept or clinical tool? Report of a WHO Expert Consultation. Diabetologia 2010; 53: 600-605.

65 Karelis AD, St-Pierre DH, Conus F, et al. Metabolic and body composition factors in subgroups of obesity: what do we know? J Clin Endocrinol Metab 2004; 89: 2569-2575.

66 Meigs JB, Wilson PWF, Fox CS, et al. Body mass index, metabolic syndrome, and risk of type 2 diabetes or cardiovascular disease. J Clin Endocrinol Metab 2006; 91: 2906-2912.

67 Manolopoulos KN, Karpe F, Frayn KN. Gluteofemoral body fat as a determinant of metabolic health. Int J Obes 2010; 34: 949-959.
68 Jensen MD. Role of body fat distribution and the metabolic complications of obesity. J Clin Endocrinol Metab 2008; 93: Suppl. 1, S57-S63.

69 Lin J-W, Caffrey JL, Chang M-H, et al. Sex, menopause, metabolic syndrome, and all-cause and cause-specific mortality - cohort analysis from the Third National Health and Nutrition Examination Survey. J Clin Endocrinol Metab 2010; 95: 4258-4267.

70 Velho S, Paccaud F, Waeber G, et al. Metabolically healthy obesity: different prevalences using different criteria. Eur J Clin Nutr 2010; 64: 1043-1051.

71 Perrini S, Laviola L, Cignarelli A, et al. Fat depot-related differences in gene expression, adiponectin secretion, and insulin action and signalling in human adipocytes differentiated in vitro from precursor stromal cells. Diabetologia 2008; 51: 155-164.

72 Pittenger MF, Mackay AM, Beck SC, et al. Multilineage potential of adult human mesenchymal stem cells. Science 1999; 284: 143-147.

73 Giorgino F, Laviola L, Eriksson JW. Regional differences of insulin action in adipose tissue: insights from in vivo and in vitro studies. Acta Physiol Scand 2005; 183: 13-30.

74 Ktotkiewski M, Sjostrom L, Bjorntorp P, et al. Regional adipose tissue cellularity in relation to metabolism in young and middleaged women. Metabolism 1975; 24: 703-710.

75 Maury E, Ehala-Aleksejev K, Guiot Y, et al. Adipokines oversecreted by omental adipose tissue in human obesity. Am J Physiol Endocrinol Metab 2007; 293: E656-E665.

76 Deng Y, Scherer PE. Adipokines as novel biomarkers and regulators of the metabolic syndrome. Ann New York Acad Sci 2010; 1212: E1-E19.

77 Myers MGJ, Leibel RL, Seeley RJ, et al. Obesity and leptin resistance: distinguishing cause from effect. Trends Endocrinol Met 2010; 21: 643-651.

78 Kanasaki K, Koya D. Biology of obesity: lessons from animal models of obesity. J Biomed Biotechnol 2011; 2011: 197636.

79 Malli F, Papaioannou AI, Gourgoulianis KI, et al. The role of leptin in the respiratory system: an overview. Respir Res 2010; 11: 152.

80 Ambrosini G, Nath AK, Sierra-Honigmann MR, et al. Transcriptional activation of the human leptin gene in response to hypoxia. J Biol Chem 2002; 277: 34601-34609.

81 Matarese G, Procaccini C, De Rosa V, et al. Regulatory T cells in obesity: the leptin connection. Trends Mol Med 2010; 16: 247-256.

82 Koh KK, Park SM, Quon MJ. Leptin and cardiovascular disease: response to therapeutic interventions. Circulation 2008; 117: 3238-3249.

83 Nawrocki AR, Rajala MW, Tomas E, et al. Mice lacking adiponectin show decreased hepatic insulin sensitivity and reduced responsiveness to peroxisome proliferator-activated receptor gamma agonists. J Biol Chem 2006; 281: 2654-2660.

84 Han SH, Sakuma I, Shin EK, et al. Antiatherosclerotic and antiinsulin resistance effects of adiponectin: basic and clinical studies. Prog Cardiovasc Dis 2009; 52: 126-140.

85 Esteve E, Ricart W, Fernandez-Real JM. Adipocytokines and insulin resistance: the possible role of lipocalin-2, retinol binding protein-4 and adiopnectin. Diabetes Care 2009; 32: Suppl. 2, S362S367.

86 Lihn AS, Bruun JM, He G, et al. Lower expression of adiponectin mRNA in visceral adipose tissue in lean and obese subjects. Mol Cell Endocrinol 2004; 219: 9-15.

87 Hirose H, Yamamoto Y, Seino-Yoshihara Y, et al. Serum highmolecular-weight adiponectin as a marker for the evaluation and care of subjects with metabolic syndrome and related disorders. I Atheroscler Thromb 2010; 17: 1201-1211.

88 Fasshauer M, Klein J, Neumann S, et al. Hormonal regulation of adiponectin gene expression in 3T3-L1 adipocytes. Biochem Biophys Res Commun 2002; 290: 1084-1089.

89 Chen B, Lam KS, Wang Y, et al. Hypoxia dysregulates the production of adiponectin and plasminogen activator inhibitor-1 
independent of reactive oxygen species in adipocytes. Biochem Biophys Res Commun 2006; 341: 549-556.

90 Magalang UJ, Cruff JP, Rajappan R, et al. Intermittent hypoxia suppresses adiponectin secretion by adipocytes. Exp Clin Endocrinol Diabetes 2009; 117: 129-134.

91 Han SH, Quon MJ, Kim J. Adiponectin and cardiovascular disease: response to therapeutic interventions. J Am Coll Cardiol 2007; 49: 531-538.

92 Hotamisligil GS, Shargill NS, Spiegelman BM. Adipose expression of tumor necrosis factor-alpha: direct role in obesity-linked insulin resistance. Science 1993; 259: 87-91.

93 Shoelson SE, Lee J, Goldfine AB. Inflammation and insulin resistance. J Clin Invest 2006; 116: 1793-1801.

94 Zeyda M, Stulnig TM. Adipose tissue macrophages. Immunol Lett 2007; 112: 61-67.

95 Solinas G, Karin M. JNK1 and IKK-beta: molecular links between obesity and metabolic dysfunction. FASEB J 2010; 24: 2596-2611.

96 Anand RJ, Gribar SC, Li J, et al. Hypoxia causes an increase in phagocytosis by macrophages in a HIF-1alpha-dependent manner. J Leukoc Biol 2007; 82: 1257-1265.

97 Ohashi K, Parker JL, Ouchi N, et al. Adiponectin promotes macrophage polarization toward an anti-inflammatory phenotype. J Biol Chem 2010; 285: 6153-6160.

98 Barbatelli MC, Pairsani V, Latini C, et al. Dead adipocytes, detected as crown-like structures, are prevalent in visceral fat depots of genetically obese mice. J Lipid Res 2008; 49: 1562-1568.

99 Lumeng CN, Bodzin JL, Saltiel AR. Obesity induces a phenotypic switch in adipose tissue macrophage polarization. J Clin Invest 2007; 117: 175-184.

100 Wentworth JM, Naselli G, Brown WA, et al. Pro-inflammatory CD11c+CD206+ adipose tissue macrophages are associated with insulin resistance in human obesity. Diabetes 2010; 59: 1648-1656.

101 Boura-Halfon S, Zick Y. Phosphorylation of IRS proteins, insulin action and insulin resistance. Am J Physiol Endocrinol Metab 2009; 296: E581-E591.

102 Varlamov O, Somwar R, Cornea A, et al. Single-cell analysis of insulin-regulated fatty acid uptake in adipocytes. Am J Physiol Endocrinol Metab 2010; 299: E486-E496.

103 O'Connell J, Lynch L, Cawood TJ, et al. The relationship of omental and subcutaneous adipocyte size to metabolic disease in severe obesity. PLoS One 2010; 5: e9997.

104 Maumus M, Sengenes C, Decaunes P, et al. Evidence of in situ proliferation of adult adipose tissue-derived progenitor cells: influence of fat mass microenvironment and growth. J Clin Endocrinol Metab 2008; 93: 4098-4106.

105 Hotamisligil GS. Inflammation and endoplasmic reticulum stress in obesity and diabetes. Int J Obes (Lond) 2008; 32: Suppl. 7, S52-S54.

106 Gao C-L, Zhua C, Zhao Y-P, et al. Mitochondrial dysfunction is induced by high levels of glucose and free fatty acids in 3T3-L1 adipocytes. Mol Cell Endocrinol 2010; 329: 25-33.

107 Trayhurn P, Wang B, Wood IS. Hypoxia and the endocrine and signalling role of white adipose tissue. Arch Physiol Biochem 2008; 114: 267-276.

108 Regazzetti C, Peraldi P, Grémeaux T, et al. Hypoxia decreases insulin signaling pathways in adipocytes. Diabetes 2009; 58: 95-103.

109 Copps KD, White MF. Breathing room: the (un)natural history of adipose microhypoxia and insulin resistance. Diabetes 2009; 58 : 26-27.

110 Pasarica M, Rood J, Ravussin E, et al. Reduced oxygenation in human obese adipose tissue is associated with impaired insulin suppression of lipolysis. J Clin Endocrinol Metab 2010; 95: 40524055.

111 Pasarica M, Sereda OR, Redman LM, et al. Reduced adipose tissue oxygenation in human obesity: evidence for rarefaction, macrophage chemotaxis, and inflammation without an angiogenic response. Diabetes 2009; 58: 718-725.
112 Dimitriadis G, Lambadiari V, Mitrou $P$, et al. Impaired postprandial blood flow in adipose tissue may be an early marker of insulin resistance in type 2 diabetes. Diabetes Care 2007; 30: 3128-3130.

113 Hosogai N, Fukuhara A, Oshima K, et al. Adipose tissue hypoxia in obesity and its impact on adipocytokine dysregulation. Diabetes 2007; 56: 901-911.

114 Ye J, Gao Z, Yin J, et al. Hypoxia is a potential risk factor for chronic inflammation and adiponectin reduction in adipose tissue of ob/ob and dietary obese mice. Am J Physiol Endocrinol Metab 2007; 293: E1118-E1128.

115 Wang B, Wood S, Trayhurn P. Dysregulation of the expression and secretion of inflammation-related adipokines by hypoxia in human adipocytes. Pflugers Arch 2007; 455: 479-492.

116 Huang LE, Bunn HF. Hypoxia-inducible factor and its biomedical relevance. J Biol Chem 2003; 278: 19575-19578.

117 Wood IS, Wang B, Lorente-Cebrián S, et al. Hypoxia increases expression of selective facilitative glucose transporters (GLUT) and 2-deoxy-D-glucose uptake in human adipocytes. Biochem Biophys Res Commun 2007; 361: 468-473.

118 Pérez de Heredia F, Wood IS, Trayhurn P. Hypoxia stimulates lactate release and modulates monocarboxylate transporter (MCT1, MCT2 and MCT4) expression inhuman adipocytes. Pflugers Arch 2010; 459: 509-518.

119 Wang B, Wood IS, Trayhurn P. Hypoxia induces leptin gene expression and secretion in human preadipocytes: differential effects of hypoxia on adipokine expression by preadipocytes. J Endocrinol 2008; 198: 127-134.

120 Trayhurn P, Duncan JS, Wood AM, et al. Metallothionein gene expression and secretion in white adipose tissue. Am J Physiol Regul Integr Comp Physiol 2000; 279: R2329-R2335.

121 Zhang $\mathrm{X}$, Lam KS, Ye H, et al. Adipose tissue-specific inhibition of hypoxia-inducible factor 1alpha induces obesity and glucose intolerance by impeding energy expenditure in mice. J Biol Chem 2010; 285: 32869-32877.

122 Almendros I, Farré R, Planas AM, et al. Tissue oxygenation in brain, muscle and fat in a rat model of sleep apnea: differential effect of obstructive apneas and intermittent hypoxia. Sleep 2011; 34: 1127-1133.

123 Nunemaker GS, Chen M, Pei H, et al. 12-Lipoxygenase-knockout mice are resistant to inflammatory effects of obesity induced by western diet. Am J Physiol Endocrinol Metab 2008; 295: E1065E1075.

124 Chakrabarti SK, Cole BK, Wen Y, et al. 12/15-Lipoxygenase products induce inflammation and impair insulin signaling in 3T3-L1 adipocytes. Obesity 2009; 17: 1657-1663.

125 Wen YW, Gu J, Vandenhoff GE, et al. Role of 12/15-lipoxygenase in the expression of MCP-1 in mouse macrophages. Am J Physiol Heart Circ Physiol 2008; 294: H1933-H1938.

126 Zarrouki B, Soares AF, Guichardant M, et al. The lipid peroxidation end-product 4-HNE induces COX-2 expression through p38MAPK activation in 3T3-L1 adipose cell. FEBS Lett 2007; 581: 2394-2400.

127 Singh PS, Niemczyk M, Saini D, et al. Role of electrophilic lipid peroxidation product 4-hydroxynonenal in the development of obesity in mice. Biochemistry 2008; 47: 3900-3911.

128 Lui MM, Ip MS. Disorders of glucose metabolism in sleepdisordered breathing. Clin Chest Med 2010; 31: 271-285.

129 Doherty LS, Kiely JL, Swan V, et al. Long-term effects of nasal continuous positive airway pressure therapy on cardiovascular outcomes in sleep apnea syndrome. Chest 2005; 127: 2076-2084.

130 Buchner NJ, Sanner BM, Borgel J, et al. Continuous positive airway pressure treatment of mild to moderate obstructive sleep apnea reduces cardiovascular risk. Am J Respir Crit Care Med 2007; 176: 1274-1280. 
131 Marshall NS, Wong KK, Liu PY, et al. Sleep apnea as an independent risk factor for all-cause mortality: the Busselton Health Study. Sleep 2008; 31: 1079-1085.

132 Young T, Finn L, Peppard PE, et al. Sleep disordered breathing and mortality: eighteen-year follow-up of the Wisconsin sleep cohort. Sleep 2008; 31: 1071-1078.

133 Punjabi NM, Caffo BS, Goodwin JL, et al. Sleep-disordered breathing and mortality: a prospective cohort study. PLoS Med 2009; 6: e1000132.

134 Bonsignore MR, Esquinas C, Barceló A, et al. Metabolic syndrome, insulin resistance and sleepiness in real-life obstractive sleep apnoea. Eur Respir J 2011; [Epub ahead of print DOI: 10.1183/09031936.00151110].

135 Mortimore IL, Marshall I, Wraith PK, et al. Neck and total body fat deposition in nonobese and obese patients with sleep apnea compared with that in control subjects. Am J Respir Crit Care Med 1998; 157: 280-283.

136 Kawaguchi Y, Fukumoto S, Inaba M, et al. Different impacts of neck circumference and visceral obesity on the severity of obstructive sleep apnea syndrome. Obesity 2011; 19: 276-282.

137 Preis SR, Massaro JM, Hoffmann U, et al. Neck circumference as a novel measure of cardiometabolic risk: the Framingham Heart study. J Clin Endocrinol Metab 2010; 95: 3701-3710.

138 Onat A, Hergenç G, Yüksel H, et al. Neck circumference as a measure of central obesity: Associations with metabolic syndrome and obstructive sleep apnea syndrome beyond waist circumference. Clin Nutr 2009; 28: 46-51.

139 Preis SR, Massaro JM, Robins SJ, et al. Abdominal subcutaneous and visceral adipose tissue and insulin resistance in the Framingham Heart Study. Obesity (Silver Spring) 2011; 18: 2191-2198.

140 Ip MS, Lam B, Ng MM, et al. Obstructive sleep apnea is independently associated with insulin resistance. Am J Respir Crit Care Med 2002; 165: 670-676.

141 Punjabi NM, Sorkin JD, Katzel LI, et al. Sleep-disordered breathing and insulin resistance in middle-aged and overweight men. Am J Respir Crit Care Med 2002; 165: 677-682.

142 Coughlin SR, Mawdsley L, Mugarza JA, et al. Obstructive sleep apnoea is independently associated with an increased prevalence of metabolic syndrome. Eur Heart J 2004; 25: 735-741.

143 Drager LF, Lopes HF, Maki-Nunes C, et al. The impact of obstructive sleep apnea on metabolic and inflammatory markers in consecutive patients with metabolic syndrome. PLoS One 2010; 5: e12065.

144 Gasa M, Salord N, Fortuna AM, et al. Obstructive sleep apnoea and metabolic impairment in severe obesity. Eur Respir J 2011; 38: 1089-1097.

145 Louis M, Punjabi NM. Effects of acute intermittent hypoxia on glucose metabolism in awake healthy volunteers. J Appl Physiol 2009; 106: 1538-1544.

146 Pamidi S, Aronsohn RS, Tasali E. Obstructive sleep apnea: role in the risk and severity of diabetes. Best Pract Res Clin Endocrinol Metab 2010; 24: 703-715.

147 Wilcox I, McNamara SG, Collins FL, et al. "Syndrome Z": the interaction of sleep apnoea, vascular risk factors and heart disease. Thorax 1998; 53: Suppl. 3, S25-S28.

148 Punjabi NM, et al. Do sleep disorders and associated treatments impact glucose metabolism? Drugs 2009; 69: Suppl. 2, 13-27.

149 Vgontzas AN. Does obesity play a major role in the pathogenesis of sleep apnoea and its associated manifestations via inflammation, visceral adiposity, and insulin resistance? Arch Physiol Biochem 2008; 114: 211-223.

150 Tasali E, Ip MS. Obstructive sleep apnea and metabolic syndrome: alterations in glucose metabolism and inflammation. Proc Am Thorac Soc 2008; 5: 207-217.

151 Punjabi NM, Polotsky VY. Disorders of glucose metabolism in sleep apnea. J Appl Physiol 2005; 99: 1998-2007.
152 Pallayova M, Donic V, Tomori Z. Beneficial effects of severe sleep apnea therapy on nocturnal glucose control in persons with type 2 diabetes mellitus. Diabetes Res Clin Pract 2008; 81: e8-e11.

153 Dawson A, Abel SL, Loving RT, et al. CPAP therapy of obstructive sleep apnea in type 2 diabetics improves glycemic control during sleep. J Clin Sleep Med 2008; 15: 538-542.

154 Aronsohn RS, Whitmore H, Van Cauter E, et al. Impact of untreated obstructive sleep apnea on glucose control in type 2 diabetes. Am J Respir Crit Care Med 2010; 181: 507-513.

155 Papanas N, Steiropoulos P, Nena E, et al. HbA1c is associated with severity of obstructive sleep apnea hypopnea syndrome in nondiabetic men. Vasc Health Risk Manag 2009; 5: 751-756.

156 Drager LF, Queiroz EL, Lopes HF, et al. Obstructive sleep apnea is highly prevalent and correlates with impaired glycemic control in consecutive patients with the metabolic syndrome. J Cardiometab Syndr 2009; 4: 89-95.

157 Ip MS, Lam KS, Ho C, et al. Serum leptin and vascular risk factors in obstructive sleep apnea. Chest 2000; 118: 580-586.

158 Harsch IA, Konturek PC, Koebnick C, et al. Leptin and ghrelin levels in patients with obstructive sleep apnoea: effect of CPAP treatment. Eur Respir J 2003; 22: 251-257.

159 Vgontzas AN, Papanicolaou DA, Bixler EO, et al. Sleep apnea and daytime sleepiness and fatigue: relation to visceral obesity, insulin resistance, and hypercytokinemia. J Clin Endocrinol Metab 2000; 85: 1151-1158.

160 Ozturk L, Unal M, Tamer L, et al. The association of the severity of obstructive sleep apnea with plasma leptin levels. Arch Otolaryngol Head Neck Surg 2003; 129: 538-540.

161 Tatsumi K, Kasahara Y, Kurosu K, et al. Sleep oxygen desaturation and circulating leptin in obstructive sleep apneahypopnea syndrome. Chest 2005; 127: 716-721.

162 Schafer H, Pauleit D, Sudhop T, et al. Body fat distribution, serum leptin, and cardiovascular risk factors in men with obstructive sleep apnea. Chest 2002; 122: 829-839.

163 Patel SR, Palmer LJ, Larkin EK, et al. Relationship between obstructive sleep apnea and diurnal leptin rhythms. Sleep 2004 27: 235-239.

164 Shimura R, Tatsumi K, Nakamura A, et al. Fat accumulation, leptin, and hypercapnia in obstructive sleep apnea-hypopnea syndrome. Chest 2005; 127: 543-549.

165 Sharma SK, Kumpawat S, Goel A, et al. Obesity, and not obstructive sleep apnea, is responsible for metabolic abnormalities in a cohort with sleep-disordered breathing. Sleep Med 2007; 8: 12-17.

166 Nakagawa Y, Kishida K, Kihara S, et al. Nocturnal reduction in circulating adiponectin concentrations related to hypoxic stress in severe obstructive sleep apnea-hypopnea syndrome. Am J Physiol Endocrinol Metab 2008; 294: E778-E784.

167 Carneiro G, Togeiro SM, Ribeiro-Filho FF, et al. Continuous positive airway pressure therapy improves hypoadiponectinemia in severe obese men with obstructive sleep apnea without changes in insulin resistance. Metab Syndr Relat Disord 2009; 7: 537-542.

168 Kanbay A, Kokturk O, Ciftci TU, et al. Comparison of serum adiponectin and tumor necrosis factor-alpha levels between patients with and without obstructive sleep apnea syndrome. Respiration 2008; 76: 324-330.

169 Makino S, Handa H, Suzukawa K, et al. Obstructive sleep apnoea syndrome, plasma adiponectin levels, and insulin resistance. Clin Endocrinol (Oxf) 2006; 64: 12-19.

170 Nakagawa Y, Kishida K, Kihara S, et al. Nocturnal falls and adiponectin levels in sleep apnea with abdominal obesity and impact of hypoxia-induced dysregulated adiponectin production in obese murine mesenteric adipose tissue. J Atheroscler Thromb 2011; 18: 240-247. 
171 Drager LF, Bortolotto LA, Maki-Nunes C, et al. The incremental role of obstructive sleep apnoea on markers of atherosclerosis in patients with metabolic syndrome. Atherosclerosis 2010; 208: 490-495.

172 Trombetta IC, Somers VK, Maki-Nunes C, et al. Consequences of comorbid sleep apnea in the metabolic syndrome - implications for cardiovascular risk. Sleep 2010; 33: 1193-1199.

173 Drager LF, Genta PR, Pedrosa RP, et al. Characteristics and predictors of obstructive sleep apnea in patients with systemic hypertension. Am J Cardiol 2010; 105: 1135-1139.

174 Vgontzas AN, Bixler EO, Chrousos GP. Sleep apnea is a manifestation of the metabolic syndrome. Sleep Med Rev 2005; 9: 211-224.

175 Barcelo A, Barbe F, de la Pena M, et al. Insulin resistance and daytime sleepiness in patients with sleep apnoea. Thorax 2008; 63: 946-950.

176 Nena E, Steiropoulos P, Papanas N, et al. Sleepiness as a marker of glucose deregulation in obstructive sleep apnea. Sleep Breath 2011; [Epub ahead of print DOI: 10.1007/s11325-010-0472-y].

177 Ronksley PE, Hemmelgarn BR, Heitman SJ, et al. Obstructive sleep apnoea is associated with diabetes in sleepy subjects. Thorax 2009; 64: 834-839.

178 Jun J, Polotsky VY. Sleep disordered breathing and metabolic effects: evidence from animal models. Sleep Med Clin 2007; 2: 263-277.

179 Polotsky VY, Rubin AE, Balbir A, et al. Intermittent hypoxia causes REM sleep deficits and decreases EEG delta power in NREM sleep in the C57BL/6J mouse. Sleep Med 2006; 7: 7-16.

180 Farre R, Nacher M, Serrano-Mollar A, et al. Rat model of chronic recurrent airway obstructions to study the sleep apnea syndrome. Sleep 2007; 30: 930-933.

181 Iiyori $\mathrm{N}$, Alonso LC, Li J, et al. Intermittent hypoxia causes insulin resistance in lean mice independent of autonomic activity. Am J Respir Crit Care Med 2007; 175: 851-857.

182 Polotsky VY, Li J, Punjabi NM, et al. Intermittent hypoxia increases insulin resistance in genetically obese mice. J Physiol 2003; 552: 253-264.

$183 \mathrm{Xu}$ J, Long YS, Gozal D, et al. Beta-cell death and proliferation after intermittent hypoxia: role of oxidative stress. Free Radic Biol Med 2009; 46: 783-790.

184 Yokoe T, Alonso LC, Romano LC, et al. Intermittent hypoxia reverses the diurnal glucose rhythm and causes pancreatic betacell replication in mice. J Physiol 2008; 586: 899-911.

185 Lam JCM, Lam B, Yao TJ, et al. A randomised controlled trial of nasal continuous positive airway pressure on insulin sensitivity in obstructive sleep apnoea. Eur Respir J 2010; 35: 138-145.

186 Harsch IA, Schahin SP, Radespiel-Troger M, et al. Continuous positive airway pressure treatment rapidly improves insulin sensitivity in patients with obstructive sleep apnea syndrome. Am J Respir Crit Care Med 2004; 169: 156-162.

187 Khan SE, Hull RL, Utzschneider KM. Mechanisms linking obesity to insulin resistance and type 2 diabetes. Nature 1996; 444: 840-846.

188 Schenk S, Saberi M, Olefsky JM. Insulin sensitivity: modulation by nutrients and inflammation. J Clin Invest 2008; 118: 2992-3002.

189 Sell H, Eckel J, Dietze-Schroeder D. Pathways leading to muscle insulin resistance: the muscle-fat connection. Arch Physiol Biochem 2006; 112: 105-113.

190 Taube A, Eckardt K, Eckel J. Role of lipid-derived mediators in skeletal muscle insulin resistance. Am J Physiol Endocrinol Metab 2009; 297: E1004-E1012.

191 Randle PJ, Garland PB, Hales CN, et al. The glucose fatty-acid cycle. Its role in insulin sensitivity and the metabolic disturbances of diabetes mellitus. Lancet 1963; 1: 785-789.

192 Yudkin JS, Eringa E, Stehouwer CDA. "Vasocrine" signalling from perivascular fat: a mechanism linking insulin resistance to vascular disease. Lancet 2005; 365: 1817-1820.
193 Marchesi C, Ebrahimian T, Angulo O, et al. Endothelial nitric oxide synthase uncoupling and perivascular adipose oxidative stress and inflammation contribute to vascular dysfunction in a rodent model of metabolic syndrome. Hypertension 2009; 54: 1384-1392.

194 Greenstein AS, Khavandi K, Withers SB, et al. Local inflammation and hypoxia abolish the protective anticontractile properties of perivascular fat in obese patients. Circulation 2009; 119: 1661-1670.

195 Pinnick KE, Collins SC, Londos C, et al. Pancreatic ectopic fat is characterized by adipocyte infiltration and altered lipid composition. Obesity (Silver Spring) 2008; 16: 522-530.

196 Rossi AP, Fantin F, Zamboni GA, et al. Predictors of ectopic fat accumulation in liver and pancreas in obese men and women Obesity (Silver Spring) 2011; 19: 1747-1754.

197 van der Zijl NJ, Goossens GH, Moors CC, et al. Ectopic fat storage in the pancreas, liver, and abdominal fat depots: impact on beta-cell function in individuals with impaired glucose metabolism. J Clin Endocrinol Metab 2011; 96: 459-467.

198 Vettor R, Milan G, Franzin C, et al. The origin of intermuscular adipose tissue and its pathophysiological implications. Am J Physiol Regul Integr Comp Physiol 2009; 297: E987-E998.

199 Samuel VT, Petersen KF, Shulman GI. Lipid-induced insulin resistance: unravelling the mechanism. Lancet 2010; 375: 2267-2277.

200 Sell H, Dietze-Schroeder D, Kaiser U, et al. Monocyte chemotactic protein-1 is a potential player in the negative cross-talk between adipose tissue and skeletal muscle. Endocrinology 2006; 147: $2458-2467$.

201 Aron A, Zedalis D, Gregg JM, et al. Potential clinical use of cardiopulmonary exercise testing in obstructive sleep apnea hypopnea syndrome. Int J Cardiol 2009; 132: 176-186.

202 Fabbrini E, Sullivan S, Klein S. Obesity and nonalcoholic fatty liver disease: biochemical, metabolic, and clinical implications. Hepatology 2010; 51: 679-689.

203 Huang W, Metlakunta A, Dedousis N, et al. Depletion of liver Kupffer cells prevents the development of diet-induced hepatic steatosis and insulin resistance. Diabetes 2010; 59: 347-357.

204 Clark JM, Brancati FL, Diehl AM. Nonalcoholic fatty liver disease. Gastroenterology 2002; 122: 1649-1657.

205 Festi D, Colecchia A, Sacco T, et al. Hepatic steatosis in obese patients: clinical aspects and prognostic significance. Obes Rev 2004; 5: 27-42.

206 Day CP, James OF. Steatohepatitis: a tale of two "hits"? Gastroenterology 1998; 114: 842-845.

207 Diehl AM. Lessons from animal models of NASH. Hepatol Res 2005; 33: 138-144.

208 Clark JM, Diehl AM. Nonalcoholic fatty liver disease: an underrecognized cause of cryptogenic cirrhosis. J Am Med Assoc 2003; 289: 3000-3004.

209 Browning JD, Szczepaniak LS, Dobbins R, et al. Prevalence of hepatic steatosis in an urban population in the United States: impact of ethnicity. Hepatology 2004; 40: 1387-1395.

210 Hilden M, Christoffersen P, Juhl E, et al. Liver histology in a 'normal' population - examinations of 503 consecutive fatal traffic casualties. Scand J Gastroenterol 1977; 12: 593-597.

211 Clark J. The epidemiology of nonalcoholic fatty liver disease in adults. J Clin Gastroenterol 2006; 40: Suppl. 1, S5-S10.

212 McCullough AJ. Pathophysiology of nonalcoholic steatohepatitis. J Clin Gastroenterol 2006; 40: Suppl. 1, S17-S29.

213 Hesham A, Kader H. Nonalcoholic fatty liver disease in children living in the obesogenic society. World J Pediatr, 2009: 245-254.

214 Postic C, Girard J. Contribution of de novo fatty acid synthesis to hepatic steatosis and insulin resistance: lessons from genetically engineered mice. J Clin Invest 2008; 118: 829-838. 
215 Fabbrini E, Magkos F, Mohammed BS, et al. Intrahepatic fat, not visceral fat, is linked with metabolic complications of obesity. Proc Natl Acad Sci USA 2009; 106: 15430-15435.

216 Speliotes EK, Massaro JM, Hoffmann U, et al. Fatty liver is associated with dyslipidemia and dysglycemia independent of visceral fat: the Framingham Heart Study. Hepatology 2010; 51: 1979-1987.

217 Listenberger LL, Han X, Lewis SE, et al. Triglyceride accumulation protects against fatty acid-induced lipotoxicity. Proc Natl Acad Sci USA 2003; 100: 3077-3082.

218 Donnelly KL, Smith CI, Schwarzenberger SJ, et al. Sources of fatty acids stored in liver and secreted via lipoproteins in patients with nonalcoholic fatty liver disease. J Clin Invest 2005; 115: 1343-1351.

219 Gonzales-Yanes C, Sanchez-Margalet V. Signalling mechanisms regulating lipolysis. Cell Signal 2006; 18: 401-408.

220 Puri $\mathrm{P}$, Mirshahi F, Cheung $\mathrm{O}$, et al. Activation and dysregulation of the unfolded protein response in nonalcoholic fatty liver disease. Gastroenterology 2008; 134: 568-576.

221 Lavie L. Oxidative stress-a unifying paradigm in obstructive sleep apnea and comorbidities. Prog Cardiovasc Dis 2009; 51: 303-312.

222 Barceló A, Piérola J, de la Peña M, et al. Free fatty acids and the metabolic syndrome in patients with obstructive sleep apnea. Eur Respir J 2011; 37: 1418-1423.

223 Jun JC, Drager LF, Najjar SS, et al. Effects of sleep apnea on nocturnal free fatty acids in subjects with heart failure. Sleep 2011; 34: 1207-1213.

224 Ahmed MH, Byrne CD. Obstructive sleep apnea syndrome and fatty liver: association or causal link? World J Gastroenterol 2010; 16: 4243-4252.

225 Singh H, Pollock R, Uhanova J, et al. Symptoms of obstructive sleep apnea in patients with nonalcoholic fatty liver disease. Dig Dis Sci 2005; 50: 2338-2343.

226 Mathurin P, Durand F, Ganne N, et al. Ischemic hepatitis due to obstructive sleep apnea. Gastroenterology 1995; 109: 1682-1684.

227 Saibara T, Nozaki Y, Nemoto Y, et al. Low socioeconomic status and coronary artery disease. Lancet 2002; 359: 980.

228 Trakada G, Gogos C, Tsiamita M, et al. A case of ischemic hepatitis. Sleep Breath 2004; 8: 155-159.

229 Strauss S, Gavish E, Gottlieb P, et al. Interobserver and intraobserver variability in the sonographic assessment of fatty liver. AJR Am J Roentgenol 2007; 189: W320-W323.

230 de Moura Almeida A, Cotrim HP, Barbosa DB, et al. Fatty liver disease in severe obese patients: diagnostic value of abdominal ultrasound. World J Gastroenterol 2008; 14: 1415-1418.

231 Mehta SR, Thomas EL, Bell JD, et al. Non-invasive means of measuring hepatic fat content. World J Gastroenterol 2008; 14: 3476-3483.

232 Vuppalanchi R, Chalasani N. Nonalcoholic fatty liver disease and nonalcoholic steatohepatitis: selected practical issues in their evaluation and management. Hepatology 2009; 49: 306-317.

233 Polotsky VY, Patil SP, Savransky V, et al. Obstructive sleep apnea, insulin resistance, and steatohepatitis in severe obesity. Am J Respir Crit Care Med 2009; 179: 228-234.

234 Kallwitz ER, Herdegen J, Madura J, et al. Liver enzymes and histology in obese patients with obstructive sleep apnea. J Clin Gastroenterol 2007; 41: 918-921.

235 Mishra P, Nugent C, Afendy A, et al. Apnoeic-hypopnoeic episodes during obstructive sleep apnoea are associated with histological nonalcoholic steatohepatitis. Liver Int 2008; 28: 10801086.

236 Campos GM, Bambha K, Vittinghoff E, et al. A clinical scoring system for predicting nonalcoholic steatohepatitis in morbidly obese patients. Hepatology 2008; 47: 1916-1923.

237 Jouët $\mathrm{P}$, Sabaté JM, Maillard $\mathrm{D}$, et al. Relationship between obstructive sleep apnea and liver abnormalities in morbidly obese patients: a prospective study. Obes Surg 2007; 17: 478-485.
238 Daltro C, Cotrim HP, Alves E, et al. Nonalcoholic fatty liver disease associated with sleep apnea: just a coincidence? Obes Surg 2010; 20: 1536-1543.

239 Tanné F, Gagnadoux F, Chazouillères $\mathrm{O}$, et al. Chronic liver injury during obstructive sleep apnea. Hepatology 2005; 41: 1290-1296.

240 Tatsumi K, Saibara T. Effects of obstructive sleep apnea syndrome on hepatic steatosis and nonalcoholic steatohepatitis. Hepatol Res 2005; 33: 100-104.

241 Norman D, Bardwell WA, Arosemena F, et al. Serum aminotransferase levels are associated with markers of hypoxia in patients with obstructive sleep apnea. Sleep 2008; 31: 121-126.

242 Chin K, Nakamura T, Takahashi K, et al. Effects of obstructive sleep apnea syndrome on serum aminotransferase levels in obese patients. Am J Med 2003; 114: 370-376.

243 Kohler M, Pepperell JC, Davies RJ, et al. Continuous positive airway pressure and liver enzymes in obstructive sleep apnoea: data from a randomized controlled trial. Respiration 2009; 78: 141-146.

244 Kheirandish-Gozal L, Sans Capdevila O, Kheirandish E, et al. Elevated serum aminotransferase levels in children at risk for obstructive sleep apnea. Chest 2008; 133: 92-99.

245 Verhulst SL, Jacobs S, Aerts L, et al. Sleep-disordered breathing: a new risk factor of suspected fatty liver disease in overweight children and adolescents? Sleep Breath 2009; 13: 207-210.

246 Savransky V, Bevans S, Nanayakkara A, et al. Chronic intermittent hypoxia causes hepatitis in a mouse model of dietinduced fatty liver. Am J Physiol Gastrointest Liver Physiol 2007; 293: G871-G877.

247 Takayama F, Egashira T, Kawasaki H, et al. A novel animal model on nonalcoholic steatohepatitis (NASH): hypoxemia enhances the development of NASH. J Clin Biochem Nutr 2009; 45: 335-340.

248 Savransky V, Nanayakkara A, Vivero A, et al. Chronic intermittent hypoxia predisposes to liver injury. Hepatology 2007; 45: 1007-1013.

249 Brunzell JD, Ayyobi AF. Dyslipidemia in the metabolic syndrome and type 2 diabetes melitus. Am J Med 2003; 115: Suppl. 8A, 24S-28S.

250 Ginsberg HN, MacCallum PR. The obesity, metabolic syndrome, and type 2 diabetes mellitus pandemic: part I. Increased cardiovascular disease risk and the importance of atherogenic dyslipidemia in persons with the metabolic syndrome and type 2 diabetes mellitus. J Cardiometab Syndr 2009; 4: 113-119.

251 Chirovsky DR, Fedirko V, Cui Y, et al. Prospective studies on the relationship between high-density lipoprotein cholesterol and cardiovascular risk: a systematic review. Eur J Cardiovasc Prev Rehabil 2009; 16: 404-423.

252 National Cholesterol Education Program (NCEP) Expert Panel on Detection, Evaluation, and Treatment of High Blood Cholesterol in Adults (Adult Treatment Panel III). Third Report of the National Cholesterol Education Program (NCEP) Expert Panel on Detection, Evaluation, and Treatment of High Blood Cholesterol in Adults (Adult Treatment Panel III) final report. Circulation 2002; 106: 3143-3421.

253 Adiels M, Olofsson S-O, Taskinen M-R, et al. Overproduction of very low-density lipoproteins is the hallmark of the dyslipidemia in the metabolic syndrome. Arterioscler Thromb Vasc Biol 2008; 28: 1225-1236.

254 Bamba V, Rader DJ. Obesity and atherogenic dyslipidemia. Gastroenterology 2007; 132: 2181-2190.

255 Olofsson S-O, Borèn J. Apolipoprotein B: a clinically important apolipoprotein which assembles atherogenic lipoproteins and promotes the development of atherosclerosis. J Intern Med 2005; 258: 395-410.

256 Sniderman A, Couture P, de Graaf J. Diagnosis and treatment of apolipoprotein B dyslipoproteinemias. Nature Rev Endocrinol 2010; 6: 335-346. 
257 Musunuru K. Atherogenic dyslipidemia: cardiovascular risk and dietary intervention. Lipids 2010; 45: 907-914.

258 Fujioka Y, Ishikawa Y. Remnant lipoproteins as strong key particles to atherogenesis. J Atheroscler Thromb 2009; 16: 145-154.

259 Newman AB, Nieto FJ, Guidry U, et al. Relation of sleep disordered breathing to cardiovascular disease risk factors: the Sleep Heart Health Study. Am J Epidemiol 2001; 154: 50-59.

260 Roche F, Sforza E, Pichot V, et al. Obstructive sleep apnoea/ hypopnea influences high-density lipoprotein cholesterol in the elderly. Sleep Med 2009; 10: 882-886.

261 McArdle N, Hillman D, Beilin L, et al. Metabolic risk factors for vascular disease in obstructive sleep apnea: a matched controlled study. Am J Respir Crit Care Med 2007; 175: 190-195.

262 Dorkova Z, Petrasova D, Molcanyiova A, et al. Effects of continuous positive airway pressure on cardiovascular risk profile in patients with severe obstructive sleep apnea and metabolic syndrome. Chest 2008; 134: 686-692.

263 Gozal D, Sans Capdevila O, Kheirandish-Gozal L. Metabolic alterations and systemic inflammation in obstructive sleep apnea among non-obese and obese pre-pubertal children. Am J Resp Crit Care Med 2008; 177: 1142-1149.

264 Steiropoulos P, Tsara V, Nena E, et al. Effect of continuous positive airway pressure treatment on serum cardiovascular risk factors in patients with obstructive sleep apnea-hypopnea syndrome. Chest 2007; 132: 843-851.

265 Iesato K, Tatsumi K, Saibara T, et al. Decreased lipoprotein lipase in obstructive sleep apnea syndrome. Circ J 2007; 71: 1293-1298.

266 Czerniawska J, Bielen P, Plywaczewski R, et al. Metabolic abnormalities in obstructive sleep apnea patients. Pneumonol Alergol Pol 2008; 76: 340-347.

267 Lefebvre B, Pepin JL, Baguet JP, et al. Leukotriene B4: early mediator of atherosclerosis in obstructive sleep apnoea? Eur Respir J 2008; 32: 113-120.

268 Tsioufis C, Thomopoulos K, Dimitriadism K, et al. The incremental effect of obstructive sleep apnoea syndrome on arterial stiffness in newly diagnosed essential hypertensive subjects. J Hypertens 2007; 25: 141-146.

269 Drager LF, Bortolotto LA, Lorenzi MC, et al. Early signs of atherosclerosis in obstructive sleep apnea. Am J Respir Crit Care Med 2005; 172: 613-618.

270 Tan KC, Chow WS, Lam JC, et al. HDL dysfunction in obstructive sleep apnea. Atherosclerosis 2006; 184: 377-382.

271 Tokuda F, Sando Y, Matsui H, et al. Serum levels of adipocytokines, adiponectin and leptin, in patients with obstructive sleep apnea syndrome. Intern Med 2008; 47: 1843-1849.

272 Li J, Grigoryev DN, Ye SQ, et al. Chronic intermittent hypoxia upregulates genes of lipid biosynthesis in obese mice. J Appl Physiol 2005; 99: 1643-1648.

273 Li J, Thorne LN, Punjabi NM. Intermittent hypoxia induces hyperlipidemia in lean mice. Circ Res 2005; 97: 698-706.

274 Li J, Savransky V, Nanayakkara A, et al. Hyperlipidemia and lipid peroxidation are dependent on the severity of chronic intermittent hypoxia. J Appl Physiol 2007; 102: 557-563.

275 Savransky V, Nanayakkara A, Li J, et al. Chronic intermittent hypoxia induces atherosclerosis. Am J Respir Crit Care Med 2007; 175: 1290-1297.

276 Horton JD, Goldstein JL, Brown MS. SREBPs: activators of the complete program of cholesterol and fatty acid synthesis in the liver. J Clin Invest 2002; 109: 1125-1131.

277 Li J, Nanayakkara A, Jun J, et al. Effect of deficiency in SREBP cleavage activating protein on lipid metabolism during intermittent hypoxia. Physiol Genomics 2007; 31: 273-280.

278 Savransky V, Jun J, Li J, et al. Dyslipidemia and atherosclerosis induced by chronic intermittent hypoxia are attenuated by deficiency of stearoyl coenzyme A desaturase. Circ Res 2008; 103: $1173-1180$
279 Li J, Bosch-Marce M, Nanayakkara A, et al. Altered metabolic responses to intermittent hypoxia in mice with partial deficiency of hypoxia-inducible factor-1alpha. Physiol Genomics 2006; 25: 450-457.

280 de Glisezinski I, Crampes F, Harant I, et al. Decrease of subcutaneous adipose tissue lipolysis after exposure to hypoxia during a simulated ascent of Mt Everest. Pflügers Arch 1999; 439: 134-140.

281 Rankin EB, Rha J, Selak MA, et al. Hypoxia-inducible factor 2 regulates hepatic lipid metabolism. Mol Cell Biol 2009; 29: 45274538 .

282 Drager LF, Li J, Shin MK, et al. Intermittent hypoxia inhibits clearance of triglyceride-rich lipoproteins and inactivates adipose lipoprotein lipase in a mouse model of sleep apnoea. Eur Heart J 2011; [Epub ahead of print DOI: 10.1093/eurheartj/ ehr097].

283 Ginsberg HN. New perspectives on atherogenesis: role of abnormal triglyceride-rich lipoprotein metabolism. Circulation 2002; 106: 2137-2142.

284 Wang H, Eckel RH. Lipoprotein lipase: from gene to obesity. Am J Physiol Endocrinol Metab 2009; 297: E271-E288.

285 Hall MH, Muldoon MF, Jennings JR, et al. Self-reported sleep duration is associated with the metabolic syndrome in midlife adults. Sleep 2008; 31: 635-643.

286 Jennings JR, Muldoon MF, Hall MH, et al. Self-reported sleep quality is associated with the metabolic syndrome. Sleep 2007; 30 219-223.

287 Kaneita Y, Uchiyama M, Yoshiike N, et al. Associations of usual sleep duration with serum lipid and lipoprotein levels. Sleep 2008; 31: 645-652.

288 Dochi M, Suwazono Y, Sakata K, et al. Shift work is a risk factor for increased total cholesterol level: a 14-year prospective cohort study in 6886 male workers. Occup Environ Med 2009; 66: 592-597.

289 Sookoian S, Gemma C, Fernández Gianotti T, et al. Effects of rotating shift work on biomarkers of metabolic syndrome and inflammation. J Intern Med 2007; 261: 285-292.

290 Gangwisch JE, Heymsfield SB, Boden-Albala B, et al. Sleep duration as a risk factor for diabetes incidence in a large U.S. sample. Sleep 2007; 30: 1667-1673.

291 Beihl DA, Liese AD, Haffner SM. Sleep duration as a risk factor for incident type 2 diabetes in a multiethnic cohort. Ann Epidemiol 2009; 19: 351-357.

292 Chen JC, Brunner RL, Ren H, et al. Sleep duration and risk of ischemic stroke in postmenopausal women. Stroke 2008; 39: 3185-3192.

293 Brown DL, Feskanich D, Sánchez BN, et al. Rotating night shift work and the risk of ischemic stroke. Am J Epidemiol 2009; 169: 1370-1377.

294 Fujino $Y$, Iso H, Tamakoshi A, et al. A prospective cohort study of shift work and risk of ischemic heart disease in Japanese male workers. Am J Epidemiol 2006; 164: 128-135.

295 Puttonen S, Kivimäki M, Elovainio M, et al. Shift work in young adults and carotid artery intima-media thickness: the Cardiovascular Risk in Young Finns study. Atherosclerosis 2009; 205: 608-613.

296 Lauderdale DS, Knutson KL, Rathouz PJ, et al. Cross-sectional and longitudinal associations between objectively measured sleep duration and body mass index: the CARDIA Sleep Study. Am J Epidemiol 2009; 170: 805-813.

297 Patel SR, Blackwell T, Redline S, et al. The association between sleep duration and obesity in older adults. Int J Obes 2008; 32 $1825-1834$.

298 Touchette E, Petit D, Tremblay RE, et al. Associations between sleep duration patterns and overweight/obesity at age 6. Sleep 2008; 31: 1507-1514. 
299 Stranges S, Cappuccio FP, Kandala NB, et al. Cross-sectional versus prospective associations of sleep duration with changes in relative weight and body fat distribution: the Whitehall II Study. Am J Epidemiol 2008; 167: 321-329.

300 Everson C, Szabo A. Recurrent restriction of sleep and inadequate recuperation induced both adaptive changes and pathological outcomes. Am J Physiol Regul Integr Comp Physiol 2009; 297: R1430-R1440.

301 Nedeltcheva AV, Kessler L, Imperial J, et al. Exposure to recurrent sleep restriction in the setting of high caloric intake and physical inactivity results in increased insulin resistance and reduced glucose tolerance. J Clin Endocrinol Metab 2009; 94 3242-3250.

302 Nedeltcheva AV, Kilkus JM, Imperial J, et al. Sleep curtailment is accompanied by increased intake of calories from snacks. Am J Clin Nutr 2009; 89: 126-133.

303 Spiegel K, Tasali E, Leproult R, et al. Effects of poor and short sleep on glucose metabolism and obesity risk. Nat Rev Endocrinol 2009; 5: 253-261.

304 Tasali E, Leproult R, Ehrmann DA, et al. Slow-wave sleep and the risk of type 2 diabetes in humans. Proc Natl Acad Sci USA 2008; 105: 1044-1049.

305 Vgontzas AN, Zoumakis E, Bixler EO, et al. Adverse effects of modest sleep restriction on sleepiness, performance, and inflammatory cytokines. J Clin Endocrinol Metab 2004; 89: 2119-2126.

306 Bray MS, Young ME. Circadian rhythms in the development of obesity: potential role for the circadian clock within the adipocyte. Obes Rev 2007; 8: 169-181.

307 Young ME, Bray MS. Potential role for peripheral circadian clock dyssynchrony in the pathogenesis of cardiovascular dysfunction. Sleep Med Rev 2007; 8: 656-667.

308 Prasai MJ, Goerge JT, Scott EM. Molecular clocks, type 2 diabetes and cardiovascular disease. Diabetes Vasc Dis Res 2008; 5 : 89-95.

309 Duez H, Staels B. Rev-erb $\alpha$ : an integrator of circadian rhythms and metabolism. J Appl Physiol 2009; 107: 1972-1980.

310 Scheer FA, Hilton MF, Mantzoros CS, et al. Adverse metabolic and cardiovascular consequences of circadian misalignment. Proc Natl Acad Sci USA 2009; 106: 4453-4458.

311 Stamatakis KA, Punjabi NM. Effects of sleep fragmentation on glucose metabolism in normal subjects. Chest 2010; 137: 95-101.

312 Perrini S, Leonardini A, Laviola L, et al. Biological specificity of visceral adipose tissue and therapeutic interventions. Arch Physiol Biochem 2008; 114: 277-286.

313 Knowler WC, Barrett-Connor E, Fowler SE, et al. Reduction in the incidence of type 2 diabetes with lifestyle intervention or metformin. N Engl J Med 2002; 346: 393-403.

314 Lindström J, Ilanne-Parikka $\mathrm{P}$, Peltonen $\mathrm{M}$, et al. Sustained reduction in the incidence of type 2 diabetes by lifestyle intervention: the follow-up results of the Finnish Diabetes Prevention Study. Lancet 2006; 368: 1673-1679.

315 Pannain S, Mokhlesi B. Bariatric surgery and its impact on sleep architecture, sleep-disordered breathing, and metabolism. Best Pract Res Clin Endocrinol Metab 2010; 24: 745-761.

316 Buchwald H, Avidor Y, Braunwald E, et al. Bariatric surgery. A systematic review and meta-analysis. J Am Med Assoc 2004; 292: 1724-1737.

317 Buchwald H, Estok R, Fahrbach K, et al. Trends in mortality in bariatric surgery: a systematic review and meta-analysis. Surgery 2007; 142: 621-635.

318 Cunneen SA. Review of meta-analytic comparisons of bariatric surgery with a focus on laparoscopic adjustable gastric banding. Surg Obes Relat Dis 2008; 4: Suppl. 43, S47-S55.

319 Sjöström L, Narbro K, Sjöström D, et al. Effects of bariatric surgery on mortality in Swedish obese subjects. $N$ Engl J Med 2007; 357: 741-752.
320 Pagotto U, Marsicano G, Cota D, et al. The emerging role of the endocannabinoid system in endocrine regulation and energy balance. Endocr Rev 2006; 27: 73-100.

321 Chavez-Tapia NC, Tellez-Avila FI, Bedogni G, et al. Systematic review and meta-analysis on the adverse events of rimonabant treatment: considerations for its potential use in hepatology. BMC Gastroenterol 2009; 9: 75.

322 Drucker DJ, Nauck MA. The incretin system: glucagon-like peptide-1 receptor agonists and dipeptidyl peptidase- 4 inhibitors in type 2 diabetes. Lancet 2006; 368: 1696-1705.

323 Kim D, MacConell L, Zhuang D, et al. Effects of once-weekly dosing of a long-acting release formulation of exenatide on glucose control and body weight in subjects with type 2 diabetes. Diabetes Care 2007; 30: 1487-1493.

324 Nauck MA, Frid A, Hermansen K, et al. Efficacy and safety comparison of liraglutide, glimepiride, and placebo, all in combination with metformin, in type 2 diabetes. Diabetes Care 2009; 32: 84-90.

325 Alhusaini S, McGee K, Schisano B, et al. Lipopolysaccharide, high glucose and saturated fatty acids induce endoplasmic reticulum stress in cultured primary human adipocytes: salicylate alleviates this stress. Biochem Biophys Res Commun 2010; 397: 472-478.

326 Fernández-Real JM, López-Bermejo A, Ropero $\mathrm{AB}$, et al. Salicylates increase insulin secretion in healthy obese subjects. J Clin Endocrinol Metab 2008; 93: 2523-2530.

327 Fleischman A, Shoelson SE, Bernier R, et al. Salsalate improves glycemia and inflammatory parameters in obese young adults. Diabetes Care 2008; 31: 289-294.

328 Koska J, Ortega E, Bunt JC, et al. The effect of salsalate on insulin action and glucose tolerance in obese non-diabetic patients: results of a randomised double-blind placebo-controlled study. Diabetologia 2009; 52: 385-393.

329 Li M, Cheung BMY. Pharmacotherapy for obesity. Br I Clin Pharmacol 2009; 68: 804-810.

330 Redenius R, Murphy C, O'Neill E, et al. Does CPAP lead to change in BMI? J Clin Sleep Med 2008; 4: 205-209.

331 Reichmuth KJ, Austin D, Skatrud JB, et al. Association of sleep apnea and type II diabetes: a population-based study. Am J Respir Crit Care Med 2005; 172: 1590-1595.

332 Coughlin SR, Mawdsley L, Mugarza JA, et al. Cardiovascular and metabolic effects of CPAP in obese males with OSA. Eur Respir J 2007; 29: 720-727.

333 Vgontzas AN, Zoumakis E, Bixler EO, et al. Selective effects of CPAP on sleep-apnoea associated manifestations. Eur J Clin Invest 2008; 38: 585-595.

334 West SD, Nicoll DJ, Wallace TM, et al. Effect of CPAP on insulin resistance and $\mathrm{HbA} 1 \mathrm{c}$ in men with obstructive sleep apnoea and type 2 diabetes. Thorax 2007; 62: 969-974.

335 Steiropoulos P, Papanas N, Nena E, et al. Continuous positive airway pressure treatment in patients with sleep apnoea: does it really improve glucose metabolism? Curr Diabetes Rev 2010; 6: 155-166.

336 Drager LF, Jun JC, Polotsky VY. Obstructive sleep apnea and dyslipidemia: implications for atherosclerosis. Curr Opin Endocrinol Diabetes Obes 2010; 17: 161-165.

337 Cuhadaroglu C, Utkusavas A, Ozturk L, et al. Effects of nasal CPAP treatment on insulin resistance, lipid profile, and plasma leptin in sleep apnea. Lung 2009; 187: 75-81.

338 Barcelo A, Barbe F, Llompart E, et al. Neuropeptide Y and leptin in patients with obstructive sleep apnea syndrome: role of obesity. Am J Respir Crit Care Med 2005; 171: 183-187.

339 Sanner BM, Kollhosser $\mathrm{P}$, Buechner $\mathrm{N}$, et al. Influence of treatment on leptin levels in patients with obstructive sleep apnoea. Eur Respir J 2004; 23: 601-604.

340 Trenell MI, Ward JA, Yee BJ, et al. Influence of constant positive airway pressure therapy on lipid storage, muscle metabolism 
and insulin action in obese patients with severe obstructive sleep apnoea syndrome. Diabetes Obes Metab 2007; 9: 679-687.

341 Chin $K$, Nakamura $T$, Shimizu $K$, et al. Effects of nasal continuous positive airway pressure on soluble cell adhesion molecules in patients with obstructive sleep apnea syndrome. Am J Med 2000; 109: 562-567.

342 Chin K, Shimizu K, Nakamura T, et al. Changes in intraabdominal visceral fat and serum leptin levels in patients with obstructive sleep apnea syndrome following nasal continuous positive airway pressure therapy. Circulation 1999; 100: 706-712.

343 Robinson GV, Pepperell JC, Segal HC, et al. Circulating cardiovascular risk factors in obstructive sleep apnoea: data from randomised controlled trials. Thorax 2004; 59: 777-782.

344 Shneerson J, Wright J. Lifestyle modification for obstructive sleep apnoea. Cochrane Database of Syst Rev 2001; 1: CD002875.

345 Tuomilehto HP, Seppä JM, Partinen MM, et al. Lifestyle intervention with weight reduction: first-line treatment in mild obstructive sleep apnea. Am J Respir Crit Care Med 2009; 179: 320-327.

346 Foster GD, Borradaile KE, Sanders MH, et al. A randomized study on the effect of weight loss on obstructive sleep apnea among obese patients with type 2 diabetes. Arch Intern Med 2009; 169: 1619-1626.

347 Johansson K, Neovius M, Lagerros YT, et al. Effect of a very low energy diet on moderate to severe obstructive sleep apnoea in obese men: a randomised controlled trial. BMJ 2009; 339: b4609.

348 Johansson K, Hemmingsson E, Harlid R, et al. Longer term effects of very low energy diet on obstructive sleep apnoea in cohort derived from randomised controlled trial: prospective observational follow-up study. BMJ 2011; 342: d3017.

349 Nerfeldt P, Nilsson BY, Mayor L, et al. A two-year weight reduction program in obese sleep apnea patients. J Clin Sleep Med 2010; 6: 479-486.

350 Grunstein RR, Stenlöf K, Hedner JA, et al. Two year reduction in sleep apnea symptoms and associated diabetes incidence after weight loss in severe obesity. Sleep 2007; 30: 703-710.

351 Dixon JB, Schachter LM, O'Brien PE. Polysomnography before and after weight loss in obese patients with severe sleep apnea. Int J Obes 2005; 29: 1048-1054.

352 Haines KL, Nelson LG, Gonzales R, et al. Objective evidence that bariatric surgery improves obesity-related obstructive sleep apnea. Surgery 2007; 141: 354-358.

353 Rao A, Tey BH, Ramalingam G. Obstructive sleep apnoea (OSA) patterns in bariatric surgical practice and response of OSA to weight loss after laparoscopic adjustable gastric banding (LABG). Ann Acad Med Singapore 2009; 38: 587-593.

354 Martinez D, Basile BR. Sibutramine does not worsen sleep apnea syndrome: a randomized double-blind placebo-controlled study. Sleep Med Clin 2005; 6: 467-470.

355 Yee BJ, Phillips CL, Banerjee D, et al. The effect of sibutramineassisted weight loss in men with obstructive sleep apnoea. Int J Obes 2007; 31: 161-168.

356 Phillips CL, Yee BJ, Trenell MI, et al. Changes in regional adiposity and cardio-metabolic function following a weight loss program with sibutramine in obese men with obstructive sleep apnea. J Clin Sleep Med 2009; 5: 416-421.

357 Ferland A, Poirier P, Sériès F. Sibutramine versus continuous positive airway pressure in obese obstructive sleep apnoea patients. Eur Respir J 2009; 34: 694-701.

358 Williams G. Withdrawal of sibutramine in Europe. Br Med J 2010; 340: c824.

359 Weaver TE, Grunstein RR. Adherence to continuous positive airway pressure therapy: the challenge to effective treatment. Proc Am Thorac Soc 2008; 5: 173-178.

360 Han JC, Lawlor DA, Kimm SYS. Childhood obesity. Lancet 2010; 375: 1737-1748.
361 Mohamadi A, Cooke DW. Type 2 diabetes mellitus in children and adolescents. Adolesc Med State Art Rev 2010; 21: 103-119.

362 Berenson GS, Srinivasan SR, Bao W, et al. Association between multiple cardiovascular risk factors and atherosclerosis in children and young adults. The Bogalusa Heart Study. N Engl J Med 1998; 338: 1650-1656.

363 Spicuzza L, Leonardi S, La Rosa M. Pediatric sleep apnea: early onset of the 'syndrome'? Sleep Med Rev 2009; 13: 111-122.

364 Gozal D. Sleep, sleep disorders and inflammation in children. Sleep Med 2009; 10: Suppl. 1, S12-S16.

365 Dayyat E, Kheirandish-Gozal L, Sans Capdevila O, et al. Obstructive sleep apnea in children: relative contributions of body mass index and adenotonsillar hypertrophy. Chest 2009; 136: 137-144.

366 Wang JH, Chung YS, Cho YW, et al. Palatine tonsil size in obese, overweight, and normal-weight children with sleep-disordered breathing. Otolaryngol Head Neck Surg 2010; 142: 516-519.

367 Tauman R, Gulliver TE, Krishna J, et al. Persistence of obstructive sleep apnea syndrome in children after adenotonsillectomy. J Pediatr 2006; 149: 803-808.

368 Kohler MJ, Thormaehlen S, Kennedy JD, et al. Differences in the association between obesity and obstructive sleep apnea among children and adolescents. J Clin Sleep Med 2009; 5: 506-511.

369 Arens R, Sin S, Nandalike K, et al. Upper airway structure and body fat composition in obese children with obstructive sleep apnea syndrome. Am J Respir Crit Care Med 2011; 183: 782-787.

370 Eliot SK, Carolyn MDA. Pediatric obstructive sleep apnea syndrome. Clin Chest Med 2010; 31: 221-234.

371 Zimmet P, Alberti G, Kaufman F, et al. The metabolic syndrome in children and adolescents. Lancet 2007; 369: 2059-2061.

372 Weiss R, Dziura J, Burgert TS, et al. Obesity and the metabolic syndrome in children and adolescents. N Engl J Med 2004; 350: 2362-2374.

373 Cook S, Weitzman M, Auinger P, et al. Prevalence of a metabolic syndrome phenotype in adolescents: findings from the third National Health and Nutrition Examination Survey, 1988-1994. Arch Pediatr Adolesc Med 2003; 157: 821-827.

374 de Ferranti SD, Gauvreau K, Ludwig DS, et al. ; Prevalence of the metabolic syndrome in American adolescents: findings from the third National Health and Nutrition Examination Survey. Circulation 2004; 110: 2494-2497.

375 Kelishadi R, Cook SR, Amra B, et al. Factors associated with insulin resistance and non-alcoholic fatty liver disease among youths. Atherosclerosis 2009; 204: 538-543.

376 Cali AM, Caprio S. Ectopic fat deposition and the metabolic syndrome in obese children and adolescents. Horm Res 2009; 71: 2-7.

377 Li AM, Chan MH, Chan DF, et al. Insulin and obstructive sleep apnea in obese Chinese children. Pediatr Pulmonol 2006; 41: 11751181.

378 Verhulst SL, Schrauwen N, Haentjens D, et al. Sleep disordered breathing and the metabolic syndrome in overweight and obese children and adolescents. J Pediatr 2007; 150: 608-612.

379 Hannon TS, Lee S, Chakravorty S, et al. Sleep-disordered breathing in obese adolescents is associated with visceral adiposity and markers of insulin resistance. Int J Pediatr Obes 2011; 6: 157-160.

380 Redline S, Storfer-Isser A, Rosen CL, et al. Association between metabolic syndrome and sleep-disordered breathing in adolescents. Am J Respir Crit Care Med 2007; 176: 401-408.

381 Verhulst SL, Rooman RP, Van Gaal L, et al. Is sleep-disordered breathing an additional risk factor for the metabolic syndrome in obese children and adolescents? Int J Obes (Lond) 2009; 33: 8-13.

382 Tsaoussoglou M, Bixler EO, Calhoun S, et al. Sleep-disordered breathing in obese children is associated with prevalent excessive daytime sleepiness, inflammation, and metabolic abnormalities. J Clin Endocrinol Metab 2010; 95: 143-150. 
383 Dubern B, Aggoun Y, Boule M, et al. Arterial alterations in severely obese children with obstructive sleep apnoea. Int $J$ Pediatr Obes 2010; 5: 230-236.

384 Gozal D, Kheirandish-Gozal L. Obesity and excessive daytime sleepiness in prepubertal children with obstructive sleep apnea. Pediatrics 2009; 123: 13-18.

385 Alexopoulos EI, Gletsou E, Kostadima E, et al. Effects of obstructive sleep apnea severity on serum lipid levels in Greek children with snoring. Sleep Breath 2011; 15: 625-631.

386 Tauman R, O'Brien LM, Ivanenko A, et al. Obesity rather than severity of sleep-disordered breathing as the major determinant of insulin resistance and altered lipidemia in snoring children. Pediatrics 2005; 116: 66-73.

387 Kelly A, Dougherty S, Cucchiara A, et al. Catecholamines, adiponectin, and insulin resistance as measured by HOMA in children with obstructive sleep apnea. Sleep 2010; 33: 1185-1191.

388 Deboer MD, Mendoza JP, Liu L, et al. Increased systemic inflammation overnight correlates with insulin resistance among children evaluated for obstructive sleep apnea. Sleep Breath 2011; [Epub ahead of print DOI: 10.1007/s11325-011-0499-8].

389 Tauman R, Serpero LD, Sans Capdevila O, et al. Adipokines in children with sleep-disordered breathing. Sleep 2007; 30: $443-449$.
$390 \mathrm{Li} \mathrm{AM}, \mathrm{Ng} \mathrm{C}, \mathrm{Ng} \mathrm{SK}$, et al. Adipokines in children with obstructive sleep apnea and the effects of treatment. Chest 2010; 137: 529-535.

391 Verhulst SL, Franckx H, Van Gaal L, et al. The effect of weight loss on sleep-disordered breathing in obese teenagers. Obesity (Silver Spring) 2009; 17: 1178-1183.

392 Roemmich JN, Barkley JE, D'Andrea L, et al. Increases in overweight after adenotonsillectomy in overweight children with obstructive sleep-disordered breathing are associated with decreases in motor activity and hyperactivity. Pediatrics 2006; 117: e200-e208.

393 Apostolidou MT, Alexopoulos EI, Damani E, et al. Absence of blood pressure, metabolic, and inflammatory marker changes after adenotonsillectomy for sleep apnea in Greek children. Pediatr Pulmonol 2008; 43: 550-560.

394 Waters KA, Sitha S, O'Brien LM, et al. Follow-up on metabolic markers in children treated for obstructive sleep apnea. Am J Respir Crit Care Med 2006; 174: 455-460.

395 Vijay LM, Naga C. Obstructive sleep apnea and nonalcoholic fatty liver disease: causal association or just a coincidence? Gastroenterology 2008; 134: 2178-2179.

396 Nakra N, Bhargava S, Dzuira J, et al. Sleep-disordered breathing in children with metabolic syndrome: the role of leptin and sympathetic nervous system activity and the effect of continuous positive airway pressure. Pediatrics 2008; 122: e634-e642. 